OPEN ACCESS

Edited by:

Yong Teng,

Augusta University, United States

Reviewed by:

Sergio Akira Uyemura,

University of São Paulo, Brazi

Yuanping Xiong,

The First Affiliated Hospital

of Nanchang University, China

${ }^{*}$ Correspondence:

Shi Zhou

156722229@qq.com

Zhu Zeng

zengzhu@gmc.edu.cn

${ }^{\dagger}$ These authors have contributed equally to this work

Specialty section:

This article was submitted to

Molecular Diagnostics

and Therapeutics,

a section of the journal

Frontiers in Molecular Biosciences

Received: 13 August 2020

Accepted: 13 October 2020

Published: 24 November 2020

Citation:

Long J, Zhang S, Zeng $X$ Ouyang $Y$, Wang $Y, H u Z$, Ye $Y, W u W$, Jin F, Zhou S and Zeng Z (2020) Development of an Immunogenomic Landscape-Based Prognostic Index of Head and Neck Squamous Cell

Carcinoma

Front. Mol. Biosci. 7:586344. doi: 10.3389/fmolb.2020.586344

\section{Development of an Immunogenomic Landscape-Based Prognostic Index of Head and Neck Squamous Cell Carcinoma}

\author{
Jinhua Long 1,2,3,4t, Shichao Zhang 1,2,3,5t, Xianlin Zeng ${ }^{1,2,3,5 t}$, Yan Ouyang ${ }^{1,2}$, Yun Wang 1,2,3,5, \\ Zuquan Hu ${ }^{1,2,3,5}$, Yuannong Ye ${ }^{1,2,3}$, Weili Wu ${ }^{4}$, Feng Jin', Shi Zhou ${ }^{6 *}$ and Zhu Zeng ${ }^{1,2,3,7 *}$ \\ ${ }^{1}$ School of Basic Medical Sciences, Guizhou Medical University, Guiyang, China, ${ }^{2}$ School of Biology and Engineering, \\ Guizhou Medical University, Guiyang, China, ${ }^{3}$ Key Laboratory of Infectious Immune and Antibody Engineering in Guizhou \\ Province, Guizhou Medical University, Guiyang, China, ${ }^{4}$ Department of Head and Neck Oncology, The Affiliated Hospital \\ of Guizhou Medical University, Guiyang, China, ${ }^{5}$ Key Laboratory of Biology and Medical Engineering, Immune Cells \\ and Antibody Engineering Research Center of Guizhou Province, School of Biology and Engineering, Guizhou Medical \\ University, Guiyang, China, ${ }^{6}$ Department of Intervention, The Affiliated Hospital of Guizhou Medical University, Guiyang, \\ China, ${ }^{7}$ Key Laboratory of Environmental Pollution Monitoring and Disease Control, Ministry of Education, Guizhou Medical \\ University, Guiyang, China
}

Head and neck squamous cell carcinoma (HNSCC) is the eighth leading cancer by incidence worldwide, with approximately 700,000 new cases in 2018 (accounting for $11 \%$ of all cancers). The occurrence and development of tumors are closely related to the immunological function of the body and sensitivity to treatment schemes as well as prognosis. It is urgent for clinicians to systematically study patients' immune gene maps to help select a treatment plan and analyze the potential to cure HNSCC. Here, the transcriptomic data of HNSCC samples were downloaded from The Cancer Genome Atlas (TCGA), and 4,793 genes differentially expressed in normal and cancer tissues of HNSCC were identified, including 1,182 downregulated and 3,611 upregulated genes. From these genes, 400 differentially expressed immune-related genes (IRGs) were extracted, including 95 downregulated genes and 305 upregulated genes. The prognostic values of IRGs were evaluated by univariate Cox analysis, and 236 genes that were significantly related to the overall survival (OS) of patients were identified. The signaling pathways that play roles in the prognosis of IRGs were investigated by Gene Ontology (GO) and Kyoto Encyclopedia of Genes and Genomes (KEGG) analyses, and the expression profiles of IRGs and OS in 499 HNSCC patients based on TCGA dataset were integrated. Potential molecular mechanisms and characteristics of these HNSCC-specific IRGs were further explored with the help of a new prognostic index based on IRGs developed by least absolute shrinkage and selection operator (LASSO) Cox analysis. A total of 64 hub genes (IRGs associated with prognosis) were markedly associated with the clinical outcome of HNSCC patients. KEGG functional enrichment analysis revealed that these genes were actively involved in several pathways, e.g., cytokine-cytokine receptor interaction, T-cell receptor signaling, and natural killer cell-mediated cytotoxicity. IRG-based prognostic signatures performed moderately in prognostic predictions. Interestingly, the prognostic index based on IRGs 
reflected infiltration by several types of immune cells. These data screened several IRGs of clinical significance and revealed drivers of the immune repertoire, demonstrating the importance of a personalized IRG-based immune signature in the recognition, surveillance, and prognosis of HNSCC.

Keywords: head and neck squamous cell carcinoma, cancer immunology, bioinformatics, immunogenomic landscape, prognostic index

\section{INTRODUCTION}

Head and neck squamous cell carcinoma (HNSCC) encompasses a heterogeneous group of epithelial malignancies that arise in the oral cavity, oropharynx, larynx, or hypopharynx (Cramer et al., 2019). Worldwide, HNSCC is the eighth leading cancer and accounts for over 700,000 new cancer cases and 350,000 deaths each year. Every year, 4-7\% of patients with HNSCC develop distant metastasis, which is common in the head and neck, lung, and esophagus. Approximately half of newly diagnosed patients will not survive beyond 5 years. At diagnosis, $45 \%$ of patients already show regional lymph node metastasis (Leemans et al., 2018; Cramer et al., 2019). Moreover, the rate of distant metastasis in HNSCC patients is exceptionally high (Leemans et al., 2018). At present, the clinical treatments for HNSCC mainly include surgery, radiotherapy, chemotherapy, molecular targeting, and immunotherapy (Cramer et al., 2019). The formation of distant metastasis after surgery is one of the main reasons for the decline in the long-term survival rate of HNSCC (Cramer et al., 2019). The immune system modifications noted in HNSCC patients suggest that this cancer is an overall immunosuppressive process (Jin and Qin, 2020). In the peripheral bloodstream, HNSCC patients have a lower overall number of white blood cells, which comprise a greater proportion of suppressive regulatory $\mathrm{T}$ cells (Tregs) (Jin and Qin, 2020). Existing treatments are insufficient for patients with locally advanced or distantly metastatic HNSCC. Careful monitoring of the progression of HNSCC with the help of novel and sensitive biomarkers could reduce the number of HNSCC patients not diagnosed before the onset of aggressive disease.

In the middle of the last century, Burnt and Thomas proposed the theory of immune surveillance, which suggests that the immune system of the host can recognize precursors of cancer and, in most cases, destroy these precursors before they become clinically apparent (Li et al., 2020). After attack by the innate immune system, tumor antigens (TAs) are released and captured by antigen-presenting cells (APCs) and then processed and loaded onto the major histocompatibility complex (MHC), activating effector $\mathrm{T}$ cells. However, cancer cells can create an immunosuppressive microenvironment through manipulation of their own immunogenicity, production of immunosuppressive mediators, and promotion of immunomodulatory cell types, leading to immune tolerance and escape ( $\mathrm{Li}$ et al., 2020). Therefore, immune normalization treatments and cancer immunotherapy have been major drivers of personalized medicine, with aggressive efforts to leverage the immune system to fight tumors (Sanmamed and Chen, 2018). The immune system has been recognized to be fundamental to the development, establishment, and spread of HNSCC. At present, several cutting-edge immunotherapies provide HNSCC patients with other alternative treatment protocols, e.g., monoclonal antibodies, immune checkpoint inhibitors (ICIs), and cell immunotherapy. Clinical trials show that patients with HNSCC can benefit from programmed cell death 1 (PD1)/programmed cell death ligand 1 (PD-L1) therapy (one type of ICI) and obtain a better quality of life (Leemans et al., 2018; Cramer et al., 2019). There are plenty of immune cells in the microenvironment of HNSCC, but their functions are not well defined (Leemans et al., 2018). Furthermore, biomarkers that can accurately predict the response of patients with HNSCC to immunotherapy are still lacking, and their applications can help patients classify and select clinical treatment protocols (Cramer et al., 2019). Most recently, large-scale gene expression datasets enable cancer researchers to efficiently identify biomarkers for tumor monitoring and surveillance. Several researchers have comprehensively investigated the prognostic value of immunerelated genes (IRGs) to build a personalized immune signature that can ameliorate prognostic estimations for patients with non-squamous non-small-cell lung cancer, papillary thyroid cancer, breast cancer, and renal cell carcinoma (Zhang S. C. et al., 2019; Zhang S. et al., 2019). IRGs play a vital role in the immune system that can control the immune response, including cytokine-related genes, chemokine-related genes, and other cell surface antigen genes. However, the clinical relevance and prognostic significance of IRGs in HNSCC are still elusive. In this study, IRG expression profiles were integrated with clinical information by computational methods for the evaluation of overall survival (OS) in HNSCC patients with the goal of gaining insight into the potential clinical application of IRGs in prognostic stratification and their implicational potential as biomarkers for targeted HNSCC therapy. On this basis, the expression status and prognostic landscape of IRGs were systematically analyzed, and an individualized prognostic signature for HNSCC patients was developed. The underlying molecular regulatory mechanisms were explored by bioinformatics. This study lays a theoretical foundation for further understanding the pathophysiological process and clinical individualized treatment of HNSCC.

\section{MATERIALS AND METHODS}

\section{Clinical Samples and Data Acquisition}

Transcriptome RNA-sequencing data of 499 primary HNSCC and 44 non-tumor tissue samples were acquired from TCGA 
data portal ${ }^{1}$. Clinical information for these patients was obtained from the same source. Lists of IRGs were exported from the Immunology Database and Analysis Portal (ImmPort) database (Bhattacharya et al., 2014).

\section{Differential Gene Analysis}

To filter IRGs involved in the incidence of HNSCC, differentially expressed IRGs between HNSCC and adjacent non-tumor tissue samples were screened via the Wilcoxon signed-rank test. False discovery rate $(\mathrm{FDR})<0.05$ and $\log _{2} \mid$ fold change $>1$ were chosen as the cutoff values for differential gene analysis of all transcriptional data. Differentially expressed IRGs were then selected from all differentially expressed genes.

\section{Survival Analysis}

Survival-associated IRGs were selected by univariate Cox analysis using R software survival package. Survival-related IRGs were also submitted for functional enrichment analysis.

\section{Molecular Characteristics of Hub Immune-Related Genes}

Hub IRGs are differentially expressed IRGs that significantly correlated with clinical outcomes of HNSCC. Copy number alterations data were acquired from TCGA Copy Number Portal $^{2}$ (Gao et al., 2013). To explore the interactions between hub IRGs, a protein-protein interaction (PPI) network was constructed based on the data gathered from the STRING online database ${ }^{3}$. The PPI network could visually display the direct or indirect interactions between hub IRGs. PPI results were visualized using Cytoscape (version 3.7.1) (He et al., 2018). To study the regulatory mechanisms of hub IRGs, regulatory links between potential transcription factors (TFs) and hub IRGs were built based on the Cistrome Cancer database. The Cistrome Cancer database stored cancer genomics data from TCGA along with over 23,000 ChIP-seq and chromatin accessibility profiles, which makes it an ideal tool for exploring the regulatory links between TFs and transcriptomes (Mei et al., 2017).

\section{Development of the Immune-Related Gene-Based Prognostic Index}

Hub IRGs were submitted for least absolute shrinkage and selection operator (LASSO) Cox regression analyses, while integrated IRGs remaining as independent prognostic indicators for developing the immune-related gene-based prognostic index (IRGPI). Patient datasets were divided into high- and low-risk groups based on their median PI-value. The prognostic value of the PI was assessed in patients with different subtypes of HNSCC. The TIMER online database stored abundance information of tumor-infiltrating immune cells and provide useful interfaces for analyzing and visualizing them ( $\mathrm{Li}$ et al., 2017). TIMER also reanalyzed gene expression data, with estimation of abundance of six subtypes of tumor-infiltrating immune cells, including B cells, $\mathrm{CD}^{+} \mathrm{T}$ cells, $\mathrm{CD}^{+} \mathrm{T}$ cells, macrophages, neutrophils,

${ }^{1}$ https://cancergenome.nih.gov/

${ }^{2}$ http://portals.broadinstitute.org/

${ }^{3}$ https://string-db.org/ and dendritic cells (DCs) from 10,897 samples across 32 cancer types from TCGA. Therefore, it can be easily employed for determining the relationship between immune cell infiltration with cancer prognosis. In this study, the associations between immune infiltrate levels of HNSCC samples and their IRGPI level were calculated.

\section{Statistical Analysis}

Gene functional enrichment analyses were conducted based on the $\mathrm{R}$ software cluster Profiler package for identifying biological themes among gene clusters (Yu et al., 2012). The area under the curve (AUC) of the survival receiver operating characteristic (ROC) curve was calculated using $\mathrm{R}$ software survival ROC package for validating the performance of the prognostic signature (Heagerty et al., 2000).

\section{RESULTS}

\section{Identification of Differentially Expressed Immune-Related Genes}

The Wilcoxon signed-rank test identified 4,793 differentially expressed genes, of which 3,611 were upregulated and 1,182 were downregulated (Figures 1A,C). From this set of genes, 400 differentially expressed IRGs were extracted, including 305 upregulated and 95 downregulated genes (Figures 1B,D).

\section{Identification of Survival-Associated Immune-Related Genes}

Disease stage and classification are important bases for clinical decision-making and individualized therapy; therefore, one of the main targets of this study is to identify potential molecular biomarkers that could serve as significant clinical prognostic indicators. Univariate Cox analysis identified 236 IRGs that have significant correlations with OS in HNSCC patients. As predicted, gene functional enrichment analysis confirmed that the immune response was most frequently implicated. The most frequently appearing biological terms among biological processes, cellular components, and molecular functions are "inflammatory response," "plasma membrane," and "cytokine activity" (Figure 2A). Kyoto Encyclopedia of Genes and Genomes (KEGG) pathways showed that cytokine-cytokine receptor interactions were most often enriched by survivalassociated IRGs (Figure 2B).

\section{Identification and Characteristics of Hub Immune Genes}

To explore actively participating IRGs in the incidence and progression of HNSCC, we ascertained 64 IRGs that are differentially expressed and related to survival as hub IRGs (Table 1), including six chemokine-related genes, six interleukin (IL)-related genes, 12 growth factor-related genes, five protease-related genes, seven T- and B-cell surface moleculerelated genes, six kinase-related genes, and 22 genes encoding other proteins. These IRGs showed excellent potential for monitoring prognostic biomarkers. A forest plot of hazard ratios (HRs) showed that most of these genes were protective 
A

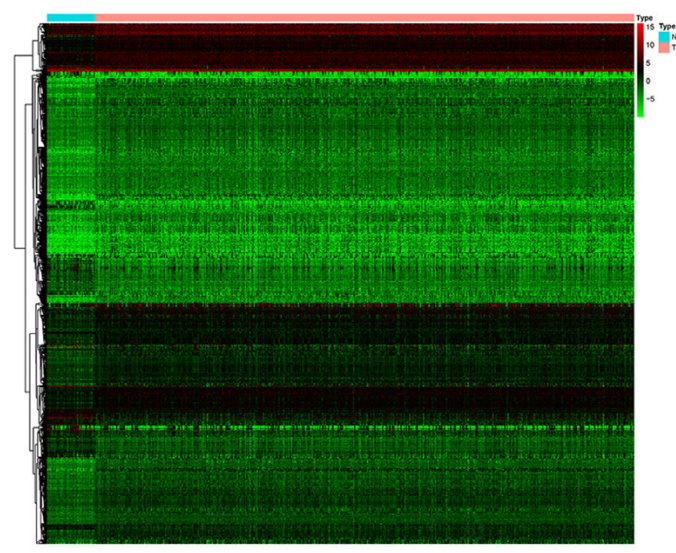

C

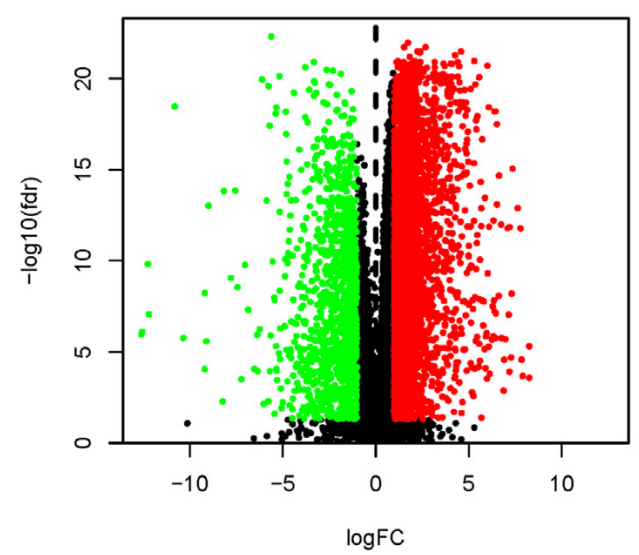

B

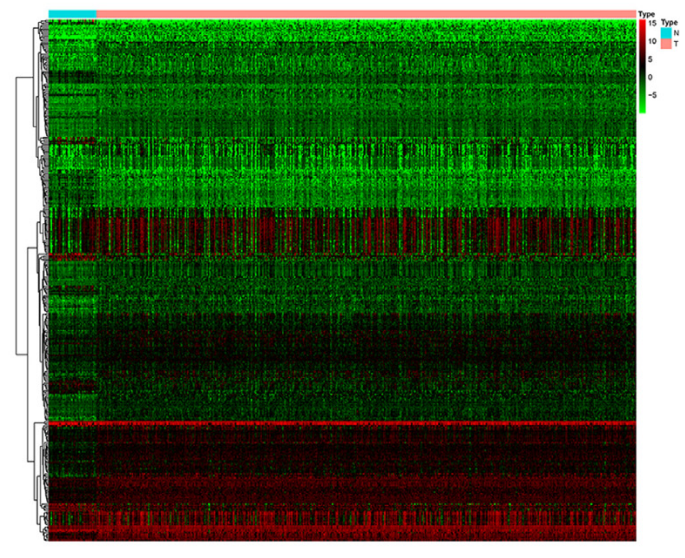

D

Volcano

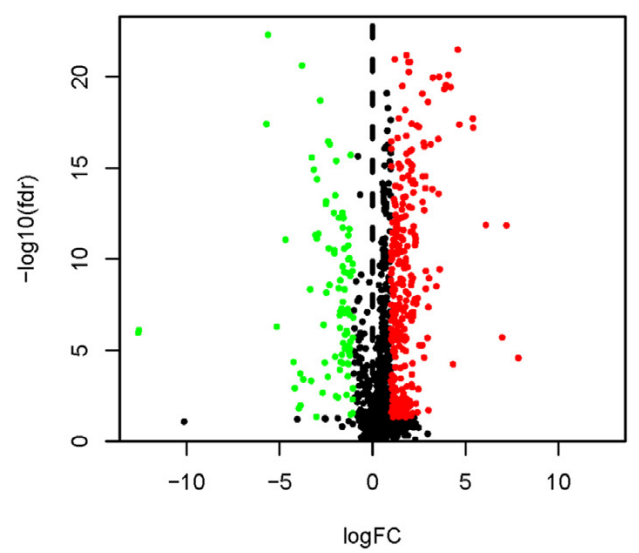

FIGURE 1 | Differentially expressed immune-related genes (IRG). The heat map (A) and volcano map (C) indicate the differentially expressed genes between head and neck squamous cell carcinoma (HNSCC) tissues and normal tissues. Red dot indicates upregulated genes, green dot indicates downregulated genes, and black dot indicates genes without a difference. In the heat map (B) and volcano map (D), differentially expressed IRGs are shown. The red dot indicates the highly expressed genes, the green dot indicates the downregulated genes, and the black dot indicates the genes with no difference.

\section{A}

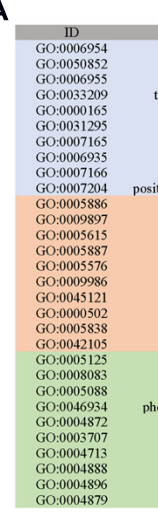

B

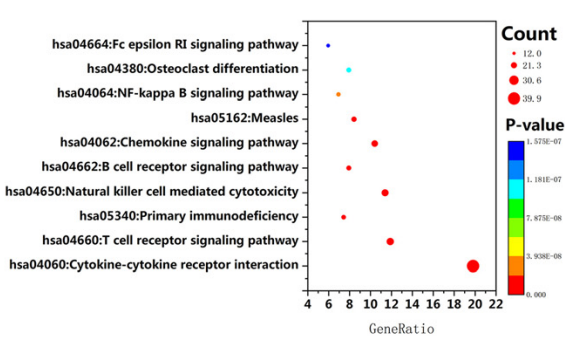

FIGURE 2 | Gene function enrichment of immune-related genes related to survival. (A) Gene Ontology (GO) analysis; blue, red, and green bars represent biological processes, cellular components, and molecular functions, respectively. (B) The 10 most significant Kyoto Encyclopedia of Genes and Genomes (KEGG) signaling pathways. 
TABLE 1 | The tumor-associated function of 56 core IRGs.

\begin{tabular}{|c|c|c|c|}
\hline Types & No./Gene names & Functions & References \\
\hline \multirow[t]{6}{*}{$\begin{array}{l}\text { Chemokine-related } \\
\text { genes }\end{array}$} & $\begin{array}{l}\text { CXC motif chemokine receptor } 4 \\
\text { (CXCR4) }\end{array}$ & $\begin{array}{l}\text { Tumor proliferation, angiogenesis, invasion. Migration promoted through } \\
\text { MMP-2/MMP-9 or MEK1/2 and ERK1/2 pathways }\end{array}$ & $\begin{array}{l}\text { González-Arriagada } \\
\text { et al., } 2018\end{array}$ \\
\hline & $\begin{array}{l}\text { CXC motif chemokine receptor } 3 \\
\text { (CXCR3) }\end{array}$ & $\begin{array}{l}\text { Induction of cytoskeletal remodeling and EMT through the AKT pathway, } \\
\text { invasion, and metastasis of tongue squamous cell carcinoma }\end{array}$ & Li Z. et al., 2018 \\
\hline & $\begin{array}{l}\text { CXC motif chemokine ligand } 13 \\
\text { (CXCL13) }\end{array}$ & Promotes osteoclast activation and OSCC invasion & $\begin{array}{l}\text { Sambandam et al., } \\
2013\end{array}$ \\
\hline & CXC motif chemokine ligand 2 (CXCL2) & $\begin{array}{l}\text { Affects the expression of CDK4, cell proliferation in esophageal cancer, Bone } \\
\text { destruction }\end{array}$ & Wang et al., 2009 \\
\hline & CC motif chemokine ligand 26 (CCL26) & $\begin{array}{l}\text { Binding to CCR3 receptors increases the expression of IL } 6 \text { and IL } 8 \text { and } \\
\text { promotes tumor invasion }\end{array}$ & Sun et al., 2018 \\
\hline & CC motif chemokine receptor 8 (CCR8) & Regulates the function of $\mathrm{T}_{\text {reg }}$ and promotes tumor migration and invasion & Liu et al., 2019 \\
\hline \multirow[t]{6}{*}{$\begin{array}{l}\text { Interleukin- related } \\
\text { genes }\end{array}$} & Interleukin1 $\beta(I L 1 \beta)$ & $\begin{array}{l}\text { The CCL22-CCR4-FOXp3 pathway is involved in tumor genesis and } \\
\text { development }\end{array}$ & Li et al., 2019 \\
\hline & Interleukin 21 receptor (IL21R) & Affects the migration of cancer cells through the MMP pathway & León et al., 2015 \\
\hline & Interleukin $1 \alpha(\mathrm{IL} 1 \alpha)$ & Participates in the inflammatory process & Li et al., 2019 \\
\hline & Interleukin 34 (IL34) & $\begin{array}{l}\text { Promotes the differentiation of monocytes and macrophages, tumor growth, } \\
\text { metastasis, and angiogenesis }\end{array}$ & Endo et al., 2020 \\
\hline & $\begin{array}{l}\text { Interleukin } 27 \text { receptor subunit } \alpha \\
(\text { IL } 27 R \alpha)\end{array}$ & Mediates inflammatory response, T lymphocyte infiltration & Sénécal et al., 2016 \\
\hline & Interleukin 2 receptor subunit $\gamma(\mathrm{IL} 2 \mathrm{R} \gamma)$ & Regulates the differentiation of multiple lymphocyte lineages & Goh and Hong, 2017 \\
\hline \multirow{12}{*}{$\begin{array}{l}\text { Growth } \\
\text { factor-related } \\
\text { genes }\end{array}$} & Colony-stimulating factor 2 (CSF2) & $\begin{array}{l}\text { GM-CSF stimulates HNSCC cell invasion and metastasis by upregulating } \\
\text { MMP-2 and MMP-14 expression }\end{array}$ & Hong, 2016 \\
\hline & Lymphotoxin $\alpha(\mathrm{LT} \alpha)$ & $\begin{array}{l}\text { Regulating the TNFR/NF-кB signaling pathway mediates PFKF33-dependent } \\
\text { glycolysis and promotes tumor angiogenesis of HNSCC }\end{array}$ & Lauenborg et al., 2015 \\
\hline & $\begin{array}{l}\text { TNF receptor superfamily member } 12 \alpha \\
(\text { TNFRSF12 } \alpha \text { ) }\end{array}$ & Stimulation of the NF-кB signaling pathway. As a prognostic marker for PTC & Qiu et al., 2018 \\
\hline & $\begin{array}{l}\text { TNF receptor superfamily member } 25 \\
\text { (TNFRSF25) }\end{array}$ & $\begin{array}{l}\text { Enhanced T cell memory in patients with metastatic HNSCC. Stimulates NF-кB } \\
\text { activity and regulates apoptosis }\end{array}$ & Schreiber et al., 2012 \\
\hline & $\begin{array}{l}\text { TNF receptor superfamily member } 4 \\
\text { (TNFRSF4) }\end{array}$ & $\begin{array}{l}\text { Activating NF-кB promotes the expression of apoptosis inhibitors BCL2 and } \\
\text { BCL2IL1/BCL2-XL, thereby inhibiting apoptosis }\end{array}$ & Schreiber et al., 2012 \\
\hline & Interferon regulatory factor 9 (IRF9) & The antiproliferative activity of IFN is mediated by the JAK-STAT pathway & Nan et al., 2018 \\
\hline & Inhibin subunit $\beta A(I N H \beta A)$ & The TGF- $\beta /$ Smad pathway is activated to regulate EMT & Chen et al., 2019 \\
\hline & Transforming growth factor- $\beta_{3}$ (TGF- $\left.\beta_{3}\right)$ & The main inducer of EMT, promotes the growth and metastasis of HNSCC & Qin et al., 2016 \\
\hline & $\begin{array}{l}\text { Platelet-derived growth factor receptor } \\
\beta \text { (PDGFR } \beta \text { ) }\end{array}$ & $\begin{array}{l}\text { Facilitates the rearrangement of actin cytoskeleton and proliferation of tumor } \\
\text { cells }\end{array}$ & Song et al., 2017 \\
\hline & Endothelin receptor type $\beta$ (EDNR $\beta$ ) & $\begin{array}{l}\text { Promotes the growth of tumor cells in tongue squamous cell carcinoma by } \\
\text { MAPK pathway }\end{array}$ & Vasaikar et al., 2018 \\
\hline & $\begin{array}{l}\text { Platelet-derived growth factor subunit A } \\
\text { (PDGFA) }\end{array}$ & Promotes the proliferation and migration of mesenchymal cells & Song et al., 2017 \\
\hline & $\begin{array}{l}\text { Vascular endothelial growth factor C } \\
\text { (VEGFC) }\end{array}$ & Promotes angiogenesis and lymphangiogenesis, immune escape & Miao et al., 2018 \\
\hline \multirow[t]{5}{*}{$\begin{array}{l}\text { Protease-related } \\
\text { genes }\end{array}$} & $\begin{array}{l}\text { Zeta chain of T cell receptor-associated } \\
\text { protein kinase } 70 \text { (ZAP70) }\end{array}$ & $\begin{array}{l}\text { Bcl-2 expression is upregulated by } \mathrm{NF}-\kappa \mathrm{B} \text { and } \mathrm{AKT} \text { pathways, promoting tumor } \\
\text { metastasis }\end{array}$ & Gladkikh et al., 2017 \\
\hline & Granzyme B (GZMB) & CTL activation is also an important effector molecule of NK cytotoxicity & Mhaidat et al., 2014 \\
\hline & $\begin{array}{l}\text { Plasminogen activator, urokinase } \\
\text { (PLAU) }\end{array}$ & Promotes tumor migration and invasion & Magnussen et al., 2014 \\
\hline & $\begin{array}{l}\text { Plasminogen activator, urokinase } \\
\text { receptor (PLAUR) }\end{array}$ & Associated with poor prognosis of OSCC & Magnussen et al., 2014 \\
\hline & $\begin{array}{l}\text { Proteasome 26S subunit, non-ATPase } \\
2 \text { (PSMD2) }\end{array}$ & The cell cycle of the $G_{0} / G_{1}$ phase is regulated by $P 21$ and/or $P 27$ & Li Y. et al., 2018 \\
\hline \multirow{7}{*}{$\begin{array}{l}\text { T and B cell surface } \\
\text { molecule-related } \\
\text { genes }\end{array}$} & CD19 & It forms a complex with CD21 that blocks the B cell receptor signaling pathway & Liu et al., 2020 \\
\hline & CD79A & Promotes tumor genesis and metastasis & Luger et al., 2013 \\
\hline & Programmed cell death 1 (PACD1) & Mediated immune escape & Ran and Yang, 2017 \\
\hline & CD22 & CD19 signal transduction is inhibited by B cell receptors and co-receptors & Kim et al., 2020 \\
\hline & Inducible T cell costimulatory (ICOS) & Cell signaling, immune response, and cell proliferation & Fan et al., 2020 \\
\hline & SH2 domain-containing 1A (SH2D1A) & Mediates two-way stimulation of $\mathrm{T}$ cells and $\mathrm{B}$ cells & $\begin{array}{l}\text { Koochakzadeh et al., } \\
2015\end{array}$ \\
\hline & CD247 & As a biomarker for PTC & Ye et al., 2019 \\
\hline
\end{tabular}


TABLE 1 | Continued

\begin{tabular}{|c|c|c|c|}
\hline Types & No./Gene names & Functions & References \\
\hline \multirow{6}{*}{$\begin{array}{l}\text { Kinase-related } \\
\text { genes }\end{array}$} & Gastrin (GAST) & Regulates autophagy through the STK11-Prkaa2-ULk1 pathway & Rao et al., 2017 \\
\hline & $\begin{array}{l}\text { Gonadotropin-releasing hormone } 1 \\
(\mathrm{GNRH} 1)\end{array}$ & $\begin{array}{l}\text { Participates in the self-renewal and dry maintenance of lung cancer stem } \\
\text { cell-like cells through upregulation of the JNK signaling pathway }\end{array}$ & Lu et al., 2015 \\
\hline & Stanniocalcin1 (STC1) & $\begin{array}{l}\text { Promotes apoptosis by phosphorylation of P65 by PI3K/AKT, IKB and IKK } \\
\text { signaling }\end{array}$ & Pan et al., 2017 \\
\hline & Stanniocalcin2 (STC2) & Promotes HNSCC migration by regulating PI3K/AKT/Snail signaling pathway & Xue et al., 2019 \\
\hline & Androgen receptor (AR) & $\begin{array}{l}\text { A shorter CAG repeat length in the gene was associated with an adverse } \\
\text { outcome in HNSCC }\end{array}$ & Rosa et al., 2007 \\
\hline & $\begin{array}{l}\text { Nuclear receptor subfamily } 3 \text { group C } \\
\text { member } 2 \text { (NR3C2) }\end{array}$ & $\begin{array}{l}\text { Mediates the effect of aldosterone on salt and water balance in restricted target } \\
\text { cells }\end{array}$ & Zhao et al., 2020 \\
\hline \multirow[t]{14}{*}{ Others } & $\begin{array}{l}\text { Baculoviral IAP repeat-containing } 5 \\
\text { (BIRC5) }\end{array}$ & Inhibits apoptosis and ensures proper chromosome separation & Frassanito et al., 2019 \\
\hline & Pentraxin 3 (PTX3) & Mediates maladjustment of mitotic signaling pathways and tumor escape & Chan et al., 2017 \\
\hline & Pleiotrophin (PTN) & $\begin{array}{l}\text { Promotion of tumor proliferation and inhibition of apoptosis-reduced } \\
\text { chemotherapy sensitivity }\end{array}$ & Zhou et al., 2018 \\
\hline & SHC adaptor protein 1 (SHC1) & $\begin{array}{l}\text { The immunosuppressive effect of STAT3 was enhanced, and the immune } \\
\text { surveillance effect of STAT1 was decreased in breast cancer }\end{array}$ & Ahn et al., 2017 \\
\hline & Retinol-binding protein 1 (RBP1) & $\begin{array}{l}\text { Contributes to the uptake of retinol. Upregulation is associated with poor } \\
\text { prognosis in TSCC }\end{array}$ & Chen et al., 2018 \\
\hline & $\begin{array}{l}\text { Progestagen associated endometrial } \\
\text { protein (PAEP) }\end{array}$ & $\begin{array}{l}\text { PAEP/glycoprotein stimulates the TGF pathway and PKC cascade. Inhibits T } \\
\text { lymphocyte activation, proliferation, and cytotoxicity }\end{array}$ & Weber et al., 2019 \\
\hline & Surfactant protein A2 (SFTPA2) & Enhances the phagocytosis and chemotaxis of alveolar macrophages & Maitra et al., 2010 \\
\hline & $\begin{array}{l}\text { Dickkopf WNT signaling pathway } \\
\text { inhibitor } 1 \text { (DKK1) }\end{array}$ & $\begin{array}{l}\text { Inhibits WNT signaling and promotes proliferation, invasion, and growth in } \\
\text { cancer cell lines }\end{array}$ & Sun et al., 2019 \\
\hline & Plexin D1 (PLXND1) & $\begin{array}{l}\text { Mediates invasion and metastasis of prostate cancer cells through } \\
\text { Notch-induced cell migration and regulation of E-cadherin }\end{array}$ & $\begin{array}{l}\text { Vivekanadhan and } \\
\text { Mukhopadhyay, } 2019\end{array}$ \\
\hline & Semaphorin 3G (SEMA3G) & Inhibition of tumor cell migration and invasion & Zhou et al., 2012 \\
\hline & B cell linker (BLNK) & Inhibits lymphocyte differentiation in tumors, leading to disease progression & Lee et al., 2020 \\
\hline & $\begin{array}{l}\text { Secreted LY6/PLAUR domain } \\
\text { containing } 1 \text { (SLURP1) }\end{array}$ & Activates cholinergic transmission and promotes T cell development & Bergqvist et al., 2018 \\
\hline & $\begin{array}{l}\text { Immunoglobulin heavy chain (including } \\
\text { IGHM, IGHV12, IGHV3.64, and } \\
\text { IGHV4.34) }\end{array}$ & $\begin{array}{l}\text { IGH gene was significantly correlated with tumor recurrence rate. Different gene } \\
\text { rearrangement affects the diversity of immunoglobulin }\end{array}$ & $\begin{array}{l}\text { Thörnqvist and Ohlin, } \\
2018\end{array}$ \\
\hline & $\begin{array}{l}\text { T cell receptor } \alpha \text { variable region } \\
\text { (Including TRAV2, TRAV4, TRAV8.3, } \\
\text { TRAV8.6, TRAV26.1, and TRBJ2.3) }\end{array}$ & $\begin{array}{l}\text { TRAV-TRAJ gene recombination is associated with antigen recognition, and the } \\
\text { diversity of TRAV genes provides more protective immunity }\end{array}$ & Pakasticali et al., 2019 \\
\hline
\end{tabular}

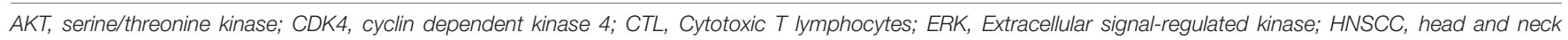
squamous cell carcinoma; IKB, inhibitor of nuclear factor kappa-B; IKK, inhibitor of nuclear factor kappa-B kinase; IRG, immune-related gene; JAK, Janus kinase; MAPK,

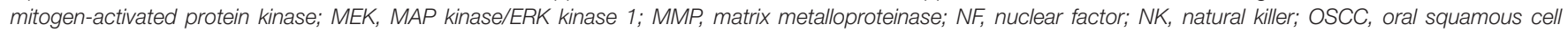

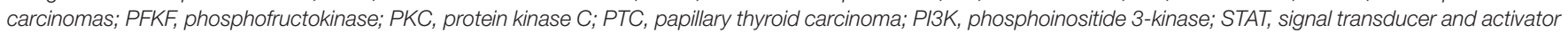
of transcription; TNF, tumor necrosis factor; TSCC, tongue squamous cell carcinoma.

factors (Figure 3A). PPI network analysis showed that some genes including colony-stimulating factor 2 (CSF2), chemokine receptors and their ligands (CXCR3, CXCR4), clusters of differentiation (CD22, CD79A), ILs (IL-1A, IL-1 $\beta$ ), Granzyme B (GZMB), programmed cell death 1 (PDCD1), zeta chainassociated protein kinase 70 (ZAP70), transforming growth factor- $\beta_{3}\left(\mathrm{TGF}-\beta_{3}\right)$, plasminogen activator urokinase (PLAU), tumor necrosis factor receptor superfamily $4,12 \mathrm{~A}$, and 25 (TNFRSF4, 12A, and 25), and inducible costimulator (ICOS) were the hub IRGs among the dataset (Figure 3B). The clinical value of these hub IRGs is significant; therefore, it is important to comprehensively explore their molecular characteristics. These hub IRGs present genomic instability (mutations and copy number alterations) in tumors of HNSCC patients, and missense mutations are the most commonly occurring type (Figures 4, 5).

\section{Transcription Factor Regulatory Network}

To investigate potential molecular mechanisms correlated with the clinical significance of the hub IRGs, we analyzed the regulatory mechanisms of these genes. We examined the expression profiles of $318 \mathrm{TFs}$ and found that 63 of them were differentially expressed between HNSCC tissues and adjacent normal tissues (Figure 6A). We then built a regulatory network to establish the link between these differentially expressed TFs and 64 previously identified hub IRGs. Correlation scores $(>0.4)$ and $p$-value $(<0.001)$ were set as the cutoff thresholds. The TF-based 
A

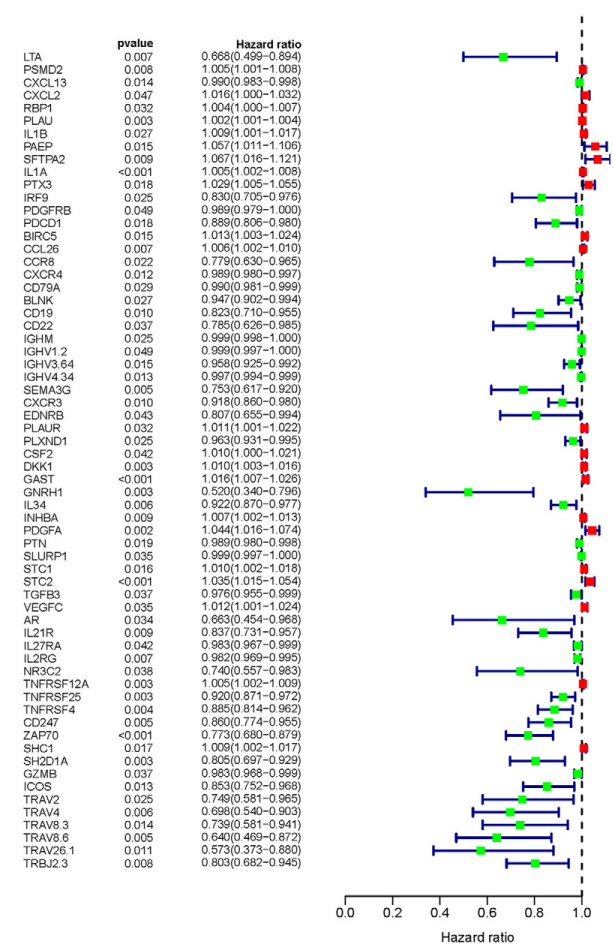

B

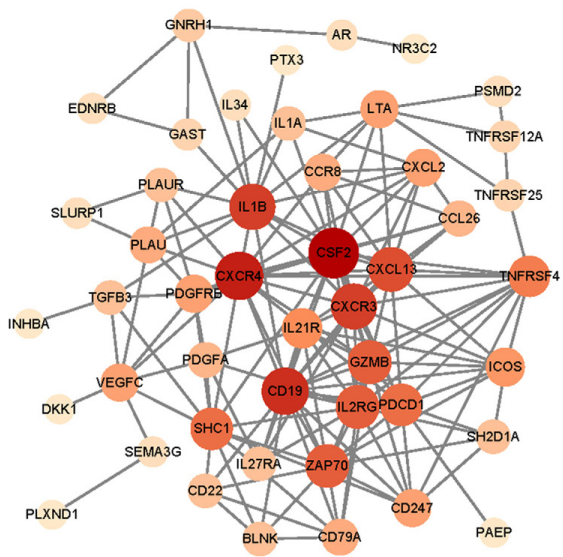

FIGURE 3 | The prognostic value of core immune genes. (A) The forest map of hazard ratio (HR) value. (B) Protein interaction network.

regulatory network demonstrated the regulatory relationships between IRGs and TFs (Figure 6B).

\section{Evaluation of Clinical Outcomes}

A prognostic signature was built based on the results of LASSO Cox regression analysis to divide the HNSCC patients into highrisk and low-risk groups (Figure 7A). The formula was as follows: [expression level of PLAU $\times$ 0.0018] + [expression level of SFTPA $2 \times 0.0557]+[$ expression level of PTX3 30.0230$]+$ [expression level of PDGFRB $\times(-0.0209)]+[$ expression level of CCL26 $\times 0.0068]+[$ expression level of CD22 $\times(-0.0790)+$ [expression level of IGHV3-64 $\times(-0.0131)]+[$ expression level of GAST $\times$ 0.0163] + [expression level of GNRH1 $\times$ $(-0.4339)]+$ [expression level of PDGFA $\times 0.0294]+$ [expression level of SLURP1 $\times(-0.0012)]+[$ expression level of STC2 $\times 0.0173]+[$ expression level of AR $\times(-0.2028)]+$ [expression level of TNFRSF25 $\times(-0.0561)$ ]. This immunebased prognostic index could be an important tool for predicting HNSCC patient outcomes. The OS rates at 3 years for the high-risk group and the low-risk group were 45.4 and $75.6 \%$, respectively. To examine the predictive accuracy of the model for OS, we used time-dependent ROC curves. The results showed that the AUC of the ROC curve was 0.742 , which has moderate survival monitoring potential for the prognostic model based on hub IRGs (Figure 7B). The risk scores and survival status of each HNSCC patient are shown in Figures $\mathbf{8 A}, \mathbf{B}$. A heat map was generated to describe the expression patterns of the risk genes in the two prognostic groups (Figure 8C). More importantly, the prognostic signature became an independent predictor after adjustment for clinical parameters, including age, gender, tumor grade, tumor stage, lymph node metastasis status, and tumor size (Figure 9).

\section{Clinical Utility of the Prognostic Signature}

To investigate whether our prognostic signature can reflect the state of HNSCC patients' tumor immune microenvironment, we evaluated the components of tumor-infiltrating immune cells in HNSCC tissues and analyzed the correlation between the risk score and the fractions of tumor-infiltrating immune cells. With an increase in the risk score, the fractions of tumor-infiltrating immune cells ( $\mathrm{CD}^{+} \mathrm{T}$ cells, $\mathrm{B}$ cells, neutrophils, macrophages, $\mathrm{CD}^{+} \mathrm{T}$ cells, and DCs) decreased (Figure 10).

\section{DISCUSSION}

It is well known that immune cells infiltrating the tumor microenvironment are considered to perform key roles in the biological behaviors of solid cancers, which are closely associated with clinical prognosis. Although the significance of IRGs in cancer generation and progression as well as immunotherapy has been proven, an integrative, genomewide profiling model correlated to their clinical significance and molecular mechanisms is not well established. This comprehensive analysis of IRGs in HNSCC helps us to understand their clinical significance and underlying molecular 


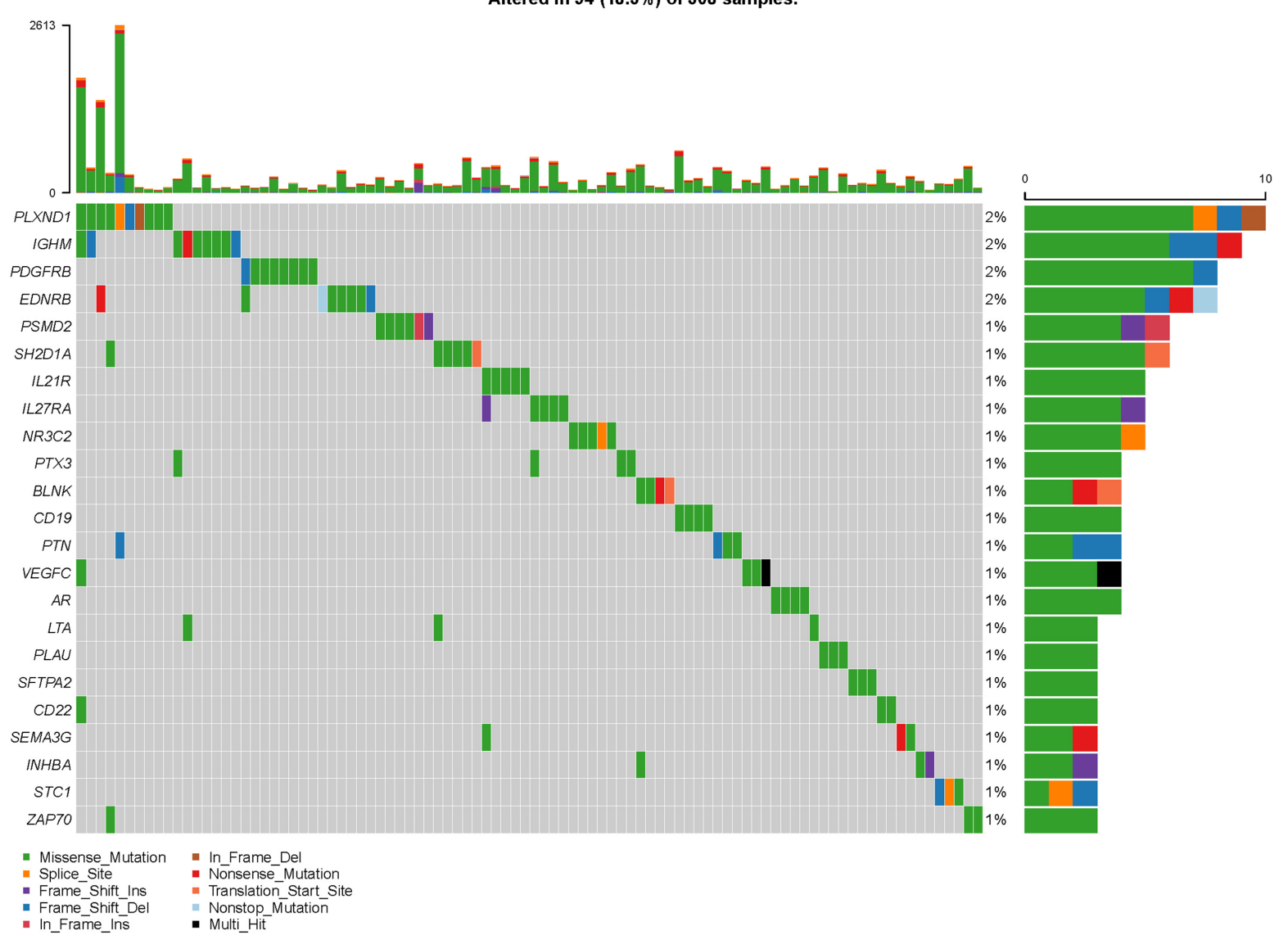

FIGURE 4 | Mutations of core immune gene.

\begin{tabular}{llllllll}
\hline \multicolumn{1}{c}{ Peak Region } & $\begin{array}{l}\text { Genes } \\
\text { Peak }\end{array}$ & in & $\begin{array}{l}\text { Residual } \\
\text { Q-value }\end{array}$ & Overall & Focal & High-level & \\
\hline chr7:708774-6341903 & PDGFA & 0.0262 & 0.398 & 0.069 & 0.034 & Frequency of \\
chr8:130919582-145232496 & SLURP1 & 0.0424 & 0.724 & 0.153 & 0.113 & Amplification \\
chr4:67184071-77688416 & CXCL2 & 0.0806 & 0.146 & 0.059 & 0.01 & & \\
chr2:220023927-242476062 & PDCD1 & $1.96 E-17$ & 0.301 & 0.199 & 0 & Frequency of \\
chr14:20501368-29233871 & IRF9;GZMB & $1.25 E-04$ & 0.149 & 0.069 & 0 & Deletions \\
chr7:117882916-158383607 & PTN & 0.0994 & 0.228 & 0.1 & 0 & \\
\hline
\end{tabular}

FIGURE 5 | Copy number variation of hub immune genes.

characteristics. A large number of HNSCC tissue samples are available from TCGA database, which ensures that the results of this study are reliable enough.

The present study identified several IRGs significantly involved in the generation and progression of HNSCC that could serve as potential valuable clinical biomarkers. Moreover, the underlying molecular mechanisms were explored by bioinformatics analyses. Importantly, a selected differentially expressed IRG-based personalization immune prognostic signature was developed for defining immune cell infiltration, and its potential clinical application value was explored. Although there is a deeper understanding of tumorigenesis and tumor immunology, many aspects of HNSCC immune-related molecular mechanisms are not well elaborated. Immunologically, the malignant transformation of cells is closely related to chronic inflammation of the local microenvironment; therefore, this study was focused on hub genes (IRGs associated with prognosis). Several studies have found differentially expressed genes between HNSCC and non-tumor tissue samples (Saada-Bouzid et al., 2019), providing intrinsic insight into the pathogenesis of HNSCC at the genetic level. However, the characteristics of IRGs in HNSCC have not been comprehensively investigated to date. Here, we concentrated on HNSCC IRGs and signaling pathways by combining immunogenomic profiles with their corresponding 
A

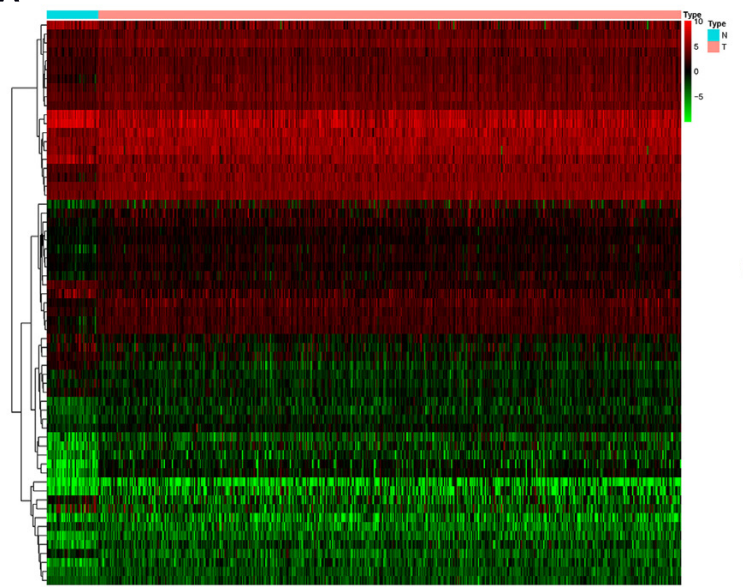

B

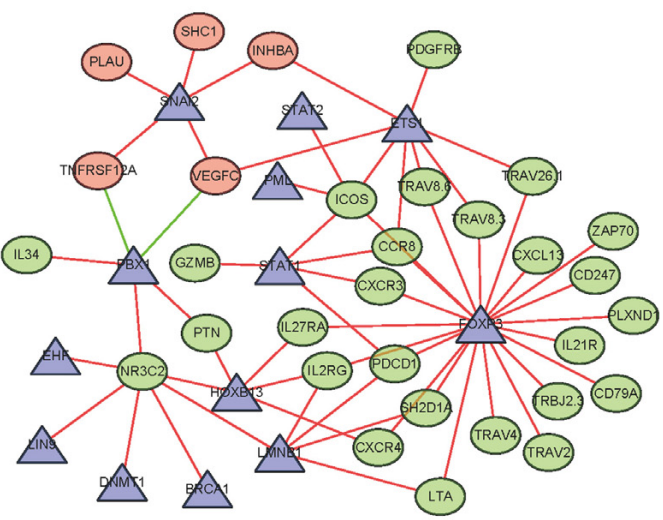

FIGURE 6 | Regulatory networks mediated by transcription factors (TFs). (A) Differentially expressed TFs. (B) A network of tumor-related TFs that regulate the expression of core immune genes. Among them, the triangle represents TFs, the green circle represents core immune genes related to good prognosis, and the red circle represents immune genes related to poor prognosis. The red line represents positive regulation, and the green line represents negative regulation.

A

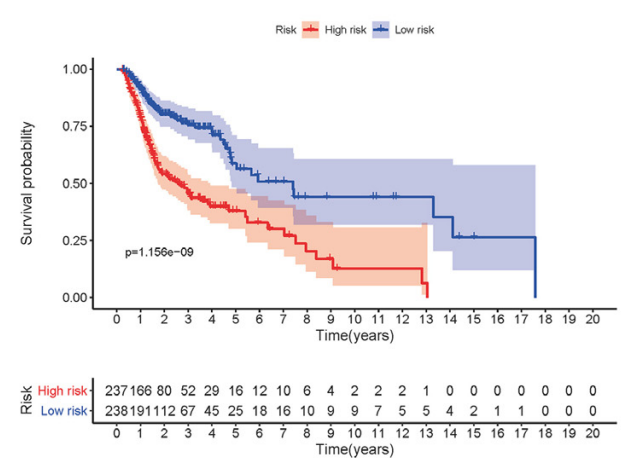

B

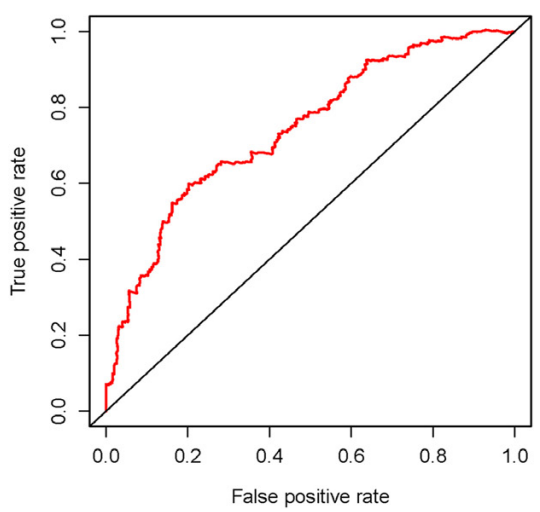

FIGURE 7 | Construction of prognosis model. (A) Patients in the high-risk group had a shorter overall survival. (B) Receiver operating characteristic (ROC) curve verification of prognosis index.

clinical significance to describe the immune status of HNSCC more comprehensively.

Through univariate Cox analysis, we found that 236 IRGs were closely related to the OS of HNSCC patients, indicating that IRGs are very important for the prognosis of HNSCC patients. CCL26, SEMA3G, DKK1, GAST, GNRH1, PDGFA, and ZAP70 genes are related to the OS of HNSCC, which is consistent with the results of Li et al. (2020). Analysis of gene function enrichment showed that these prognoses related to immune genes were mainly involved in the interaction of cytokine-cytokine receptor interactions and the nuclear factor (NF)- $\mathrm{B}$ signaling pathway. The interaction of cytokine receptors mainly involves the RAS-mitogen-activated protein kinase (MAPK) and Janus kinase (JAK)-signal transducer and activator of transcription (STAT) pathways. JAK-STAT signals control cell proliferation, differentiation, and survival by transferring external signals from the plasma membrane to the nucleus, thus participating in the occurrence, development, transfer, and drug resistance mechanism formation of HNSCC (Liu et al., 2016). The NF- $\kappa \mathrm{B}$ signaling pathway is an effective regulator of many important physiological processes, including cell proliferation, apoptosis, angiogenesis, inflammation, and immune response (Monisha et al., 2017). In previous studies, the NF-кB pathway was found to usually be activated with the progression of HNSCC, and its persistent expression is the root cause of cancer cell proliferation, invasion, and metastasis and the low survival rate of HNSCC patients (Popeda et al., 2019). Our results suggest that the BIRC5 gene might be the target gene of NF- $\kappa \mathrm{B}$, which can inhibit cell apoptosis by binding p65 and BIRC5 (Yan et al., 2013; Zeng et al., 2016), leading to HNSCC diffusion and poor prognosis; however, this needs to be verified by subsequent experiments.

In addition, we identified 64 differentially expressed and prognosis-related IRGs as core genes, including six 

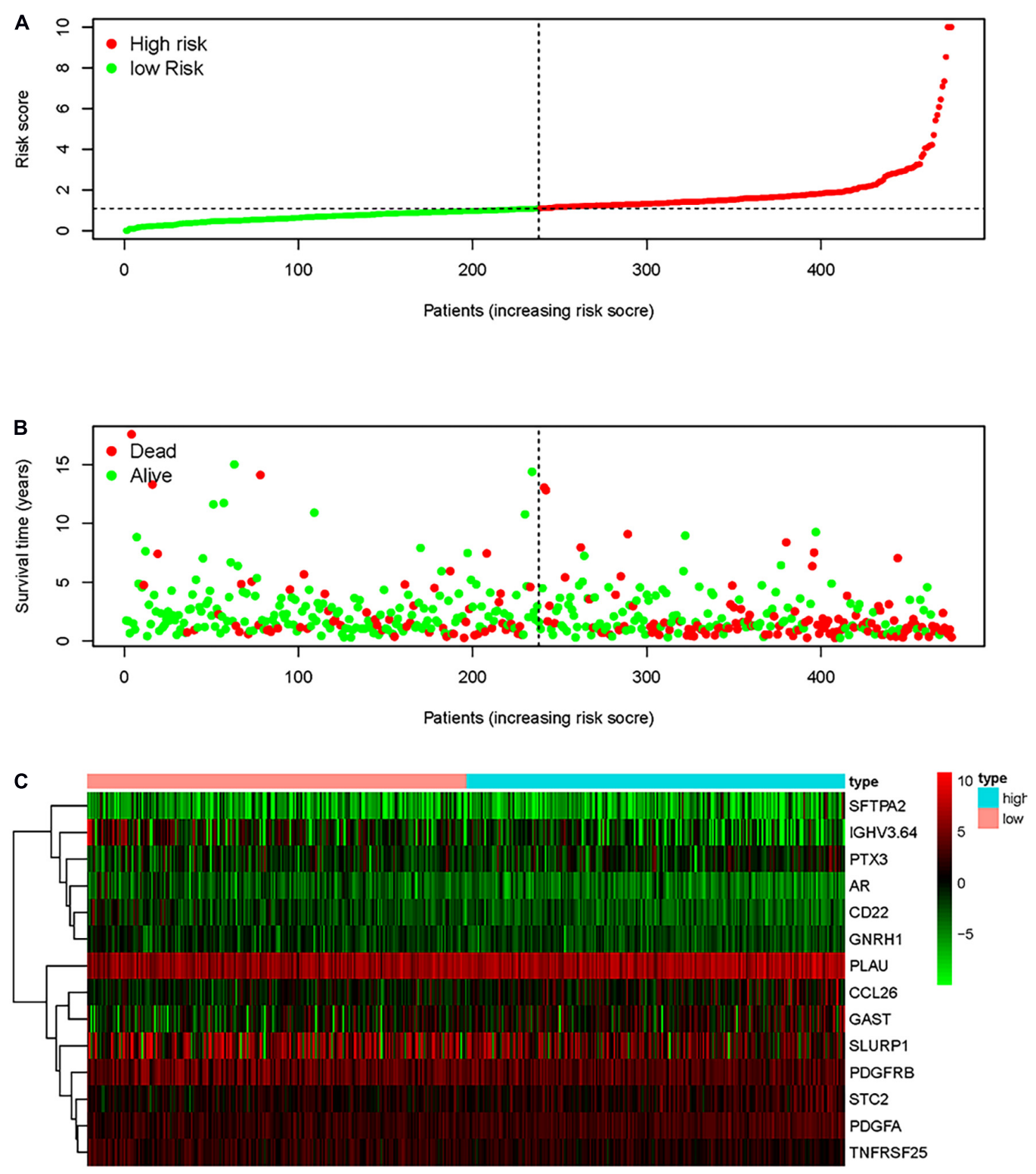

FIGURE 8 | Prognostic indicators based on core immune genes. (A) Group and distribution of prognostic indicators. (B) Survival status of patients in different groups. (C) Thermogram of the core immune genes used to construct the model.

chemokine-related genes, six IL-related genes, 12 growth factorrelated genes, five protease-related genes, seven $\mathrm{T}$ - and B-cell surface molecule-related genes, six kinase-related genes, and 22 genes encoding other proteins (Table 1). CXCR3 and CXCR4 are known to promote the proliferation, invasion, and migration of HNSCC through matrix metalloproteinase (MMP)-2/MMP-9 (González-Arriagada et al., 2018; Li Z. et al., 2018). CXCL2 and CXCL13 are associated with bone destruction in oral cancer (Wang et al., 2009; Sambandam et al., 2013) and promote tumor invasion. This is consistent with the results of our KEGG analysis. CCL26 and CCR 8 are related to the $\mathrm{Ca}^{2+}$ mobilization of cells, and CCR8 can also recruit Treg infiltration, thereby promoting tumor metastasis (Sun et al., 2018; Liu et al., 2019).
Genes related to Treg infiltration also include the IL-related gene IL-1 $\beta$, which induces Treg infiltration through the CCL22CCR4-Foxp3 pathway and participates in the development of HNSCC (Li et al., 2019). Other IL-related genes can promote tumor metastasis (León et al., 2015; Sénécal et al., 2016; Goh and Hong, 2017; Endo et al., 2020). Growth factor-related genes are also associated with tumor metastasis, among which LT $\alpha$, TNFRSF12 $\alpha$, TNFRSF25, TNFRSF4, and IRF9 can mediate HNSCC tumorigenesis and metastasis through the NF- $\kappa B$ signaling pathway (Schreiber et al., 2012; Lauenborg et al., 2015; Nan et al., 2018; Qiu et al., 2018). The NF-кB pathway was one of the important pathways in the KEGG analysis of this study. The protease-related gene ZAP70 mediates prostate cancer 


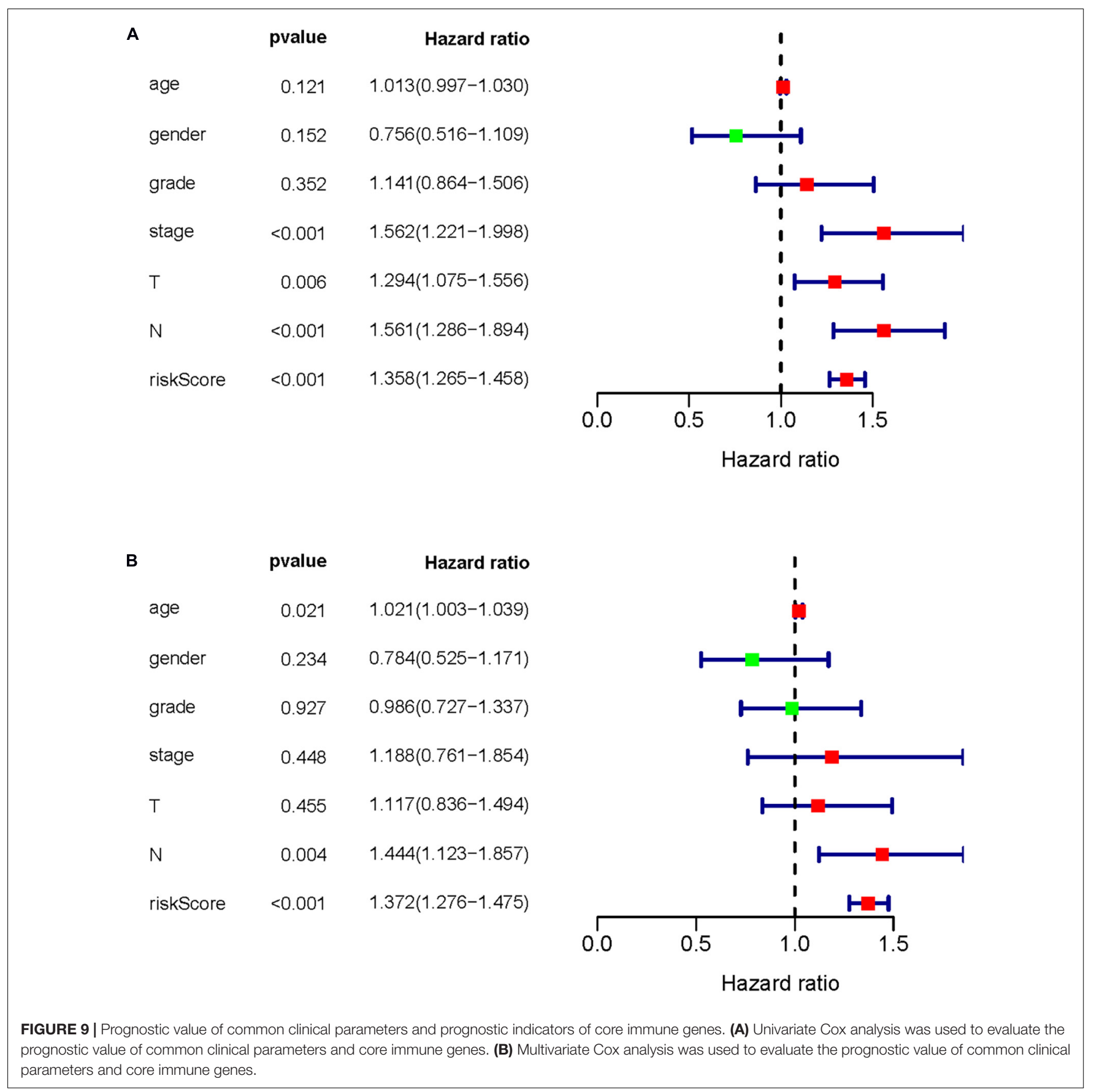

metastasis through the NF-кB pathway (Gladkikh et al., 2017). Among the seven genes related to the surface molecules of $\mathrm{T}$ and B cells, CD19 and CD79A are associated with the development and activation of B cells (Luger et al., 2013; Liu et al., 2020). PACD1 encodes PD-1 and is normally expressed in T cells, but its expression in tumor tissues is closely related to tumor immune escape (Ran and Yang, 2017). The expression of six kinds of kinase-related genes is related to the poor prognosis of the tumor. Among them, more research has been conducted on the anti-cisplatin effect of GAST (Rao et al., 2017), and GNRH1 and STC1 can activate the c-Jun N-terminal kinase (JNK) pathway to facilitate tumor development (Lu et al., 2015; Pan et al., 2017). Studies have shown that BIRC5 may be the target gene of $\mathrm{NF}-\kappa \mathrm{B}$ in genes encoding other proteins, and the expression of its apoptosis inhibitor survivin affects chromosome separation (Frassanito et al., 2019). PTX3 and PTN also affect the prognosis of tumors via the NF-кB pathway (Chan et al., 2017; Zhou et al., 2018). In addition to the NF- $\kappa B$ pathway, another important pathway, namely, the RAS/MAPK pathway, was identified in the KEGG analysis. Some studies have shown that SHC1 downregulates immune surveillance through the RAS/MAPK pathway to promote tumor development (Ahn et al., 2017). 


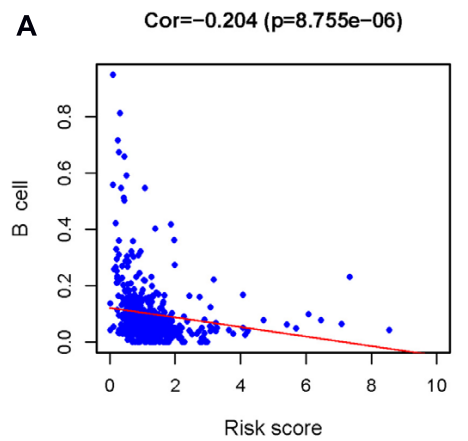

D

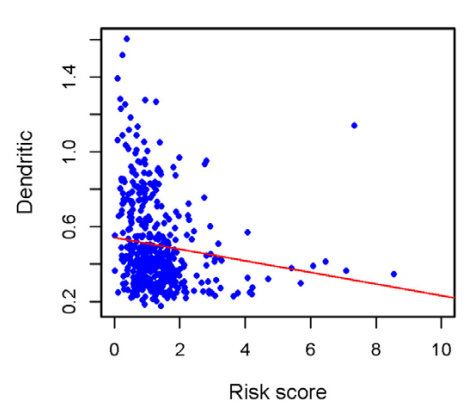

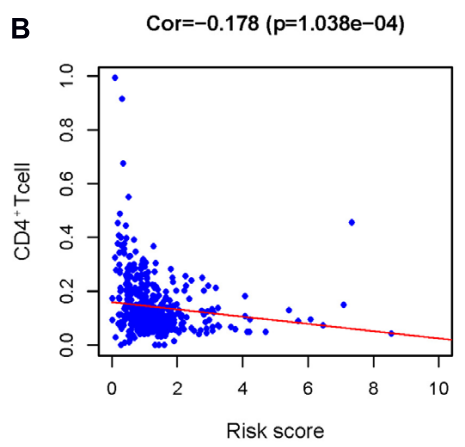

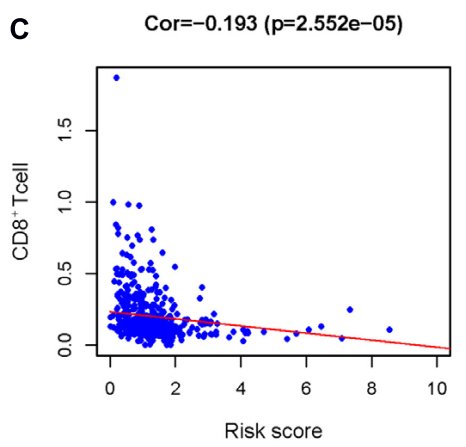

E

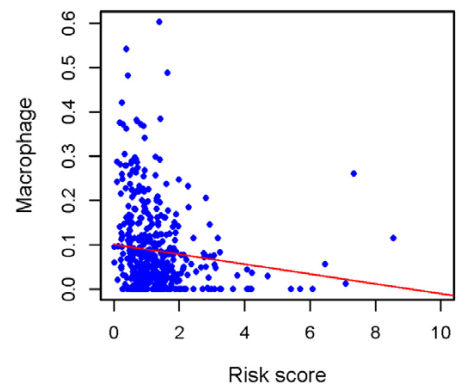

$\mathbf{F}$

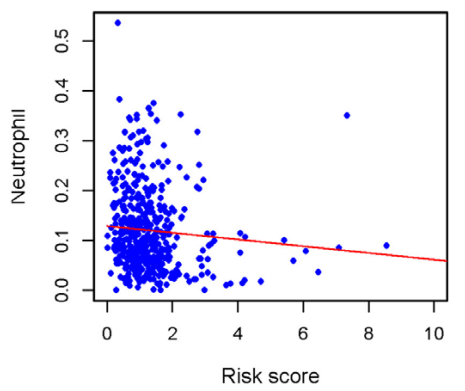

FIGURE 10 | The relationship between the prognosis index of core immune gene and the infiltration amount of six types of immune cells. Correlation analysis was performed using Pearson test. (A) B cells, (B) CD4 ${ }^{+}$T cells, (C) CD8 ${ }^{+} \mathrm{T}$ cells, (D) dendritic cells (DCs), (E) macrophages, and (F) neutrophils.

In summary, the core IRGs involve tumor-related pathways including the phosphoinositide 3-kinase (PI3K)/AKT, NF- $\mathrm{B}$, Notch, Wnt, JAK/STAT, TGF- $\beta /$ Smad, PKC, and RAS/MAPK pathways. The 5 growth factor-related genes (LT $\alpha$, TNFRSF $12 \alpha$, TNFRSF25, TNFRSF4, and IRF9) and BIRC5, PTX3, and PTN all play key roles in the occurrence and development of HNSCC mediated by the NF- $\kappa$ B pathway.

To explore the regulatory mechanism of the abnormal expression of IRGs in HNSCC, we constructed a regulatory network of core IRGs and tumor-related TFs. The results showed that FOXP3, STAT1, STAT2, SNAI2, and EHF play core roles in the network. Foxp3 regulates the differentiation and function of Tregs and coregulates Treg maturation with T-cell receptor (TCR) signaling (Ono, 2020). Core gene analysis showed that TCR diversity was determined by six genes in the TRAV family. Second, Foxp3 can also inhibit NF- $\kappa$ B transcriptional activity with P65 in TSCC (Li K. et al., 2018), contributing to the infiltration of Tregs in tumors. Previous studies have shown that the maturation of Tregs is related to TNFRSF in core genes (Schreiber et al., 2012), which indicates that Tregs play an important role in the development of HNSCC. STAT1 and STAT2 regulate interferon genes. The heterodimers of STAT1 and STAT2 enter the nucleus together with IRF9 and transcriptionally activate IFN-1. Studies have shown that STAT1 is a TF downstream of cytokines and growth factors. Reduced phosphorylation also inhibits the expression of class I antigen-processing element (APM), allowing HNSCC to evade CTL killing (Ryan et al., 2020). Phosphorylated STAT2 induces the proliferation of oral cancer cells (Hao et al., 2019). Both SNAI2 and EHF can regulate genes related to epithelial cells.
Wang et al. (2019) showed that SNAI2, as a DNA-binding TF, can promote the initiation of EMT induced by TGF- $\beta$, resulting in decreased intrinsic cell adhesion and enhanced motor ability, which is conducive to its proliferation, migration, and invasion. EHF is an epithelial-specific TF that plays an important role in maintaining normal cell homeostasis and mediating epithelial tissue differentiation. Its ectopic expression in ESCC promotes cell proliferation and invasion (Wang et al., 2019). PML, PBX1, and DNMT1 act on DNA, and PML and DNMT1 participate in DNA modification and activate/silence genes through demethylation/methylation (Gajewski et al., 2013). PBX1 enhances DNA binding and plays a role in the carcinogenesis of ESCC. In the TF network analysis, the TFs Foxp3 and SNAI2 were found to participate in regulating the expression and silencing of some core genes, providing some references for research on the genesis and development mechanism of HNSCC.

It is worth mentioning that we used univariate Cox to analyze the prognosis based on IRGs and then used LASSO Cox analysis to build the prognostic model. The results show that this model can well distinguish patients with different clinical results. We further evaluated its reliability by ROC curve analysis (the AUC of the ROC curve was 0.742). Compared with Bhattacharya et al. (2014), who only used Cox regression to establish a prognosis model for thyroid cancer, after we added LASSO regression based on Cox regression, many genes with unique values were found to control the complexity of the model through the parameter $\lambda$ to avoid overfitting. Moreover, the prognostic markers we constructed can be used as independent predictors after clinical parameter correction, yielding high clinical applicability for the prediction of HNSCC development. The establishment 
of an HNSCC prognostic model based on IRGs provides a reference for clinical treatment, which is not only helpful to assess patient condition but also helpful to further elucidate the functions of IRGs.

The theory of tumor immune escape suggests that the process of tumor generation and development can be divided into three stages: elimination, equilibrium, and escape. Tumor-infiltrating immune cells play an important role in this process. It is known that tumor-infiltrating immune cells are prognostic factors for different types of cancer, and their number and type can reflect the type of immune response in the tumor microenvironment, which is heterogeneous (Balermpas et al., 2016). Monisha et al. (2017) compared the infiltration of immune cells in normal and HNSCC tissues with CIBERSORT and discussed its clinical value (Monisha et al., 2017). They found that $\mathrm{CD}^{+}$memory $\mathrm{T}$ cells were related to the prognosis of HNSCC. Therefore, the Pearson test was utilized to analyze the relationship between the prognostic index and the infiltration quantity of six kinds of immune cells $\left(\mathrm{CD}^{+} \mathrm{T}\right.$ cells, $\mathrm{B}$ cells, neutrophils, macrophages, $\mathrm{CD}^{+} \mathrm{T}$ cells, and DCs) in this study. The results showed that with an increase in the risk value, the number of tumorinfiltrating immune cells decreased. Our prognostic index can reflect the immune microenvironment of HNSCC patients to a certain extent. Previous studies have shown that $\mathrm{CD} 8^{+} \mathrm{T}$ cells combine with MHC-I molecules to promote the cytotoxic effect of TILs in HNSCC patients, and the survival rate of patients with high CD8 expression is improved (Andreu et al., 2010). At present, the role of $\mathrm{B}$ cells in the tumor microenvironment is still controversial. Tumor-infiltrating B cells (TIL-B) can act as local APCs and provide critical secondary costimulation signals to tumor-infiltrating $\mathrm{CD}^{+} \mathrm{T}$ cells to maintain the antitumor ability mediated by $\mathrm{CD}^{+} \mathrm{T}$ cells and prolong the survival time of patients (Andreu et al., 2010). Gao et al. (2018) found that activation of Fc $\gamma \mathrm{R}$ by B lymphocytes can recruit suppressive leukocytes, thus inhibiting the antitumor immune response and promoting the progression of tumors. Tumor-associated macrophages (TAMs) can be divided into $\mathrm{M}_{1}$ (which can produce $\mathrm{Th}_{1}$ cytokines) and $\mathrm{M}_{2}$ (which secretes IL-10 and other immunosuppressive cytokines) subtypes. $\mathrm{M}_{1}$ TAMs phagocytized HNSCC cells in a CD47-dependent manner. In the study by Gao et al. (2018), HNSCC cells cocultured with monocytes were found to transform monocytes into $\mathrm{M}_{2}$ macrophages. $\mathrm{M}_{2}$ macrophage-released EGF induces epithelialmesenchymal transformation (EMT) in HNSCC cells, which promotes the migration and invasion of cancer cells (Cho et al., 2018). It has been found that increased neutrophils in the peripheral blood can lead to a poor prognosis and local infiltration and distant metastasis in HNSCC patients. Cho et al. (2018) also confirmed that neutrophils are the main sources of CCL4 and MMP9 in the tumor microenvironment, and cytokines released by neutrophils can promote the adhesion and migration of the HNSCC cell matrix; namely, the increase in neutrophils can promote the progression of HNSCC. CD4 ${ }^{+} \mathrm{T}$ cells are stimulated by different cytokines and are transformed into corresponding helper $\mathrm{T}$ cells. Some studies have shown that $\mathrm{CD}^{+}{ }^{+} \mathrm{CD} 9^{+} \mathrm{T}$ cells are associated with a good prognosis in HNSCC patients, while $\mathrm{FOXP}^{+} \mathrm{CD}^{+} \mathrm{T}$ cells are favorable for tumor progression (DeNardo et al., 2009). DCs are the most powerful APCs known and play a key role in immune responses against cancer. According to Long et al. (2019), the depletion of DCs in tumor tissue indicates a high recurrence rate and poor prognosis of HNSCC, while high infiltration of DCs is related to a better prognosis. The lack of DCs in HNSCC may lead to insufficient stimulation of cytotoxic $\mathrm{T}$ lymphocytes and the formation of Tregs, leading to tumor immune tolerance (Wischatta et al., 2000), while the presence of DCs might activate the immune monitoring system, facilitate ingestion and presentation of tumor antigens, and induce an antitumor immune response.

However, there are a few limitations in this study. First, we only used the expression data and clinical information of the HNSCC queue in TCGA database, and we should also use other databases [such as the Gene Expression Omnibus (GEO) database] for verification. Second, the molecular mechanisms of these IRGs involved in the occurrence and development of HNSCC need to be further studied by in vitro and in vivo experiments. Finally, the AUC of ROC was 0.742, suggesting that the model has moderate potential for the prognostic signature based on IRGs in survival monitoring. The model could divide patients into the high-risk group and low-risk group and predict the survival outcomes of HNSCC patients. However, it is not high enough for clinical practice. We will collect clinic samples of HNSCC patients in the next period to optimize the model and improve the value of AUC.

In conclusion, we explored the core IRGs that may play important roles in the development of HNSCC and further revealed the potential regulatory mechanisms of these core IRGs. In addition, we constructed an ideal prognosis model through LASSO Cox. These results are helpful for developing individualized treatment plans and new treatment targets for HNSCC patients.

\section{DATA AVAILABILITY STATEMENT}

Publicly available datasets were analyzed in this study. This data can be found here: https://cancergenome.nih.gov/; http://portals. broadinstitute.org/; and https://string-db.org/.

\section{AUTHOR CONTRIBUTIONS}

JL, SCZ, YO, FJ, and ZZ contributed to the conception and design. JL and SCZ contributed to the collection and assembly of data. JL, SCZ, XZ, ZH, YW, and YY contributed to the data analysis and interpretation. JL, SCZ, XZ, and ZZ contributed to the manuscript writing. $\mathrm{ZZ}, \mathrm{WW}$, and FJ contributed to the manuscript revision. All authors gave the final approval for the manuscript.

\section{FUNDING}

This research was funded by grants from the National Natural Science Foundation of China (31771014, 31660258, 
11762006, 31260227, 11162003, 8206555, and 81460254), the 2011 Collaborative Innovation Program of Guizhou Province (2015-04), the China Postdoctoral Science Foundation (2015M582747XB), the Science and Technology Innovative Talent Team of Guizhou Province (2015-4021), the Key Project of the Ministry of Education of China (210196), the Science and Technology Foundation of Guizhou Province (LH-2015-7336, LH-2016-7375, and LH-2015-7326), the Technology Foundation for Selected Overseas Chinese of

\section{REFERENCES}

Ahn, R., Sabourin, V., Bolt, A. M., Hébert, S., Totten, S., De Jay, N., et al. (2017). The Shc1 adaptor simultaneously balances Stat1 and Stat3 activity to promote breast cancer immune suppression. Nat. Commun. 8:14638. doi: 10 . 1038/ncomms 14638

Andreu, P., Johansson, M., Affara, N. I., Pucci, F., Tan, T., Junankar, S., et al. (2010). FcRgamma activation regulates inflammation-associated squamous carcinogenesis. Cancer Cell 17, 121-134. doi: 10.1016/j.ccr.2009.12.019

Balermpas, P., Rödel, F., Rödel, C., Krause, M., Linge, A., Lohaus, F., et al. (2016). CD8+ tumour-infiltrating lymphocytes in relation to HPV status and clinical outcome in patients with head and neck cancer after postoperative chemoradiotherapy: a multicentre study of the German cancer consortium radiation oncology group (DKTK-ROG). Int. J. Cancer 138, 171-181. doi: 10. 1002/ijc. 29683

Bergqvist, C., Kadara, H., Hamie, L., Nemer, G., Safi, R., Karouni, M., et al. (2018). SLURP-1 is mutated in Mal de Meleda, a potential molecular signature for melanoma and a putative squamous lineage tumor suppressor gene. Int. J. Dermatol. 57, 162-170. doi: 10.1111/ijd.13850

Bhattacharya, S., Andorf, S., Gomes, L., Dunn, P., Schaefer, H., Pontius, J., et al. (2014). ImmPort: disseminating data to the public for the future of immunology. Immunol. Res. 58, 234-239. doi: 10.1007/s12026-014-8516-1

Chan, S. H., Tsai, J. P., Shen, C. J., Liao, Y. H., and Chen, B. K. (2017). Oleateinduced PTX3 promotes head and neck squamous cell carcinoma metastasis through the up-regulation of vimentin. Oncotarget 8, 41364-41378. doi: 10 . 18632/oncotarget.17326

Chen, Y., Tian, T., Mao, M. J., Deng, W. Y., and Li, H. (2018). CRBP-1 over-expression is associated with poor prognosis in tongue squamous cell carcinoma. BMC Cancer 18:514. doi: 10.1186/s12885-018-4249-1

Chen, Z. L., Qin, L., Peng, X. B., Hu, Y., and Liu, B. (2019). INHBA gene silencing inhibits gastric cancer cell migration and invasion by impeding activation of the TGF- $\beta$ signaling pathway. J. Cell. Physiol. 234, 18065-18074. doi: 10.1002/jcp. 28439

Cho, J. K., Kim, M. W., Choi, I. S., Moon, U. Y., Kim, M. J., Sohn, I., et al. (2018). Optimal cutoff of pretreatment neutrophil-to-lymphocyte ratio in head and neck cancer patients: a meta-analysis and validation study. BMC Cancer 18:969. doi: 10.1186/s12885-018-4876-6

Cramer, J. D., Burtness, B., Le, Q. T., and Ferris, R. L. (2019). The changing therapeutic landscape of head and neck cancer. Nat. Rev. Clin. Oncol. 16, 669-683. doi: 10.1038/s41571-019-0227-z

DeNardo, D. G., Barreto, J. B., Andreu, P., Vasquez, L., Tawfik, D., Kolhatkar, N., et al. (2009). CD4(+) T cells regulate pulmonary metastasis of mammary carcinomas by enhancing protumor properties of macrophages. Cancer Cell 16, 91-102. doi: 10.1016/j.ccr.2009.06.018

Endo, H., Hama, N., Baghdadi, M., Ishikawa, K., Otsuka, R., Wada, H., et al. (2020). Interleukin-34 expression in ovarian cancer: a possible correlation with disease progression. Int. Immunol. 32, 175-186. doi: 10.1093/intimm/dxz074

Fan, X., Wang, J., Qin, T., Zhang, Y., Liu, W., Jiang, K., et al. (2020). Exosome miR$27 a-3 p$ secreted from adipocytes targets ICOS to promote antitumor immunity in lung adenocarcinoma. Thorac. Cancer 11, 1453-1464. doi: 10.1111/17597714.13411

Frassanito, M. A., Saltarella, I., Vinella, A., Muzio, L. L., Pannone, G., Fumarulo, R., et al. (2019). Survivin overexpression in head and neck squamous cell carcinomas as a new therapeutic target (Review). Oncol. Rep. 41, 2615-2624. doi: 10.3892/or.2019.7082
Guizhou Province (2013-8), and the Bureau of Science and Technology of Guiyang (20161001-029 and 2015100119).

\section{ACKNOWLEDGMENTS}

We would like to thank the ImmPort, TIMER, Cistrome Cancer, and TCGA databases for the availability of the data.

Gajewski, T. F., Schreiber, H., and Fu, Y. X. (2013). Innate and adaptive immune cells in the tumor microenvironment. Nat. Immunol. 14, 1014-1022. doi: 10. 1038/ni.2703

Gao, J., Aksoy, B. A., Dogrusoz, U., Dresdner, G., Gross, B., Sumer, S. O., et al. (2013). Integrative analysis of complex cancer genomics and clinical profiles using the cBioPortal. Sci. Signal. 6:11. doi: 10.1126/scisignal.2004088

Gao, L., Zhang, W., Zhong, W. Q., Liu, Z. J., Li, H. M., Yu, Z. L., et al. (2018). Tumor associated macrophages induce epithelial to mesenchymal transition via the EGFR/ERK1/2 pathway in head and neck squamous cell carcinoma. Oncol. Rep. 40, 2558-2572. doi: 10.3892/or.2018.6657

Gladkikh, A. A., Potashnikova, D. M., Tatarskiy, V. Jr., Yastrebova, M., Khamidullina, A., Barteneva, N., et al. (2017). Comparison of the mRNA expression profile of $\mathrm{B}$-cell receptor components in normal CD5-high B-lymphocytes and chronic lymphocytic leukemia: a key role of ZAP70. Cancer Med. 6, 2984-2997. doi: 10.1002/cam4.1257

Goh, T. S., and Hong, C. (2017). New insights of common gamma chain in hematological malignancies. Cytokine 89, 179-184. doi: 10.1016/j.cyto.2015. 12.009

González-Arriagada, W. A., Lozano-Burgos, C., Zúñiga-Moreta, R., GonzálezDíaz, P., and Coletta, R. D. (2018). Clinicopathological significance of chemokine receptor (CCR1, CCR3, CCR4, CCR5, CCR7 and CXCR4) expression in head and neck squamous cell carcinomas. J. Oral Pathol. Med. 47, 755-763. doi: 10.1111/jop.12736

Hao, Y. R., Zhang, D. J., Fu, Z. M., Guo, Y. Y., and Guan, G. F. (2019). Long non-coding RNA ANRIL promotes proliferation, clonogenicity, invasion and migration of laryngeal squamous cell carcinoma by regulating miR-181a/Snai2 axis. Regen. Ther. 11, 282-289. doi: 10.1016/j.reth.2019.07.007

He, R. Q., Zhou, X. G., Yi, Q. Y., Deng, C. W., Gao, J. M., Chen, G., et al. (2018). Prognostic signature of alternative splicing events in bladder urothelial carcinoma based on spliceseq data from 317 cases. Cell Physiol. Biochem. 48, 1355-1368. doi: 10.1159/000492094

Heagerty, P. J., Lumley, T., and Pepe, M. S. (2000). Time-dependent ROC curves for censored survival data and a diagnostic marker. Biometrics 56, 337-344. doi: 10.1111/j.0006-341x.2000.00337.x

Hong, I. S. (2016). Stimulatory versus suppressive effects of GM-CSF on tumor progression in multiple cancer types. Exp. Mol. Med. 48:e242. doi: 10.1038/ emm.2016.64

Jin, Y., and Qin, X. (2020). Profiles of immune cell infiltration and their clinical significance in head and neck squamous cell carcinoma. Int. Immunopharmacol. 82:106364. doi: 10.1016/j.intimp.2020.106364

Kim, B., Shin, J., Kiziltepe, T., and Bilgicer, B. (2020). Identification of a moderate affinity CD22 binding peptide and in vitro optimization of peptide-targeted nanoparticles for selective uptake by CD22+ B-cell malignancies. Nanoscale 12, 11672-11683. doi: 10.1039/d0nr02133d

Koochakzadeh, L., Hosseinverdi, S., Hedayat, M., Farahani, F., Tofighi, A., Eghbali, M., et al. (2015). Study of SH2D1A gene mutation in paediatric patients with B-cell lymphoma. Allergol. Immunopathol. 43, 568-570. doi: 10.1016/j.aller. 2015.01.007

Lauenborg, B., Christensen, L., Ralfkiaer, U., Kopp, K. L., Jønson, L., Dabelsteen, S., et al. (2015). Malignant T cells express lymphotoxin $\alpha$ and drive endothelial activation in cutaneous $\mathrm{T}$ cell lymphoma. Oncotarget 6, 15235-15249. doi: 10.18632/oncotarget.3837

Lee, J. H., Lee, J. H., Ahn, B. K., Paik, S. S., and Lee, K. H. (2020). Prognostic value of B-cell linker protein in colorectal cancer. Pathol. Res. Pract. 216:152821. doi: 10.1016/j.prp.2020.152821 
Leemans, C. R., Snijders, P. J. F., and Brakenhoff, R. H. (2018). The molecular landscape of head and neck cancer. Nat. Rev. Cancer 18, 269-282. doi: 10.1038/ nrc.2018.11

León, X., Bothe, C., García, J., Parreño, M., Alcolea, S., Quer, M., et al. (2015). Expression of IL- $1 \alpha$ correlates with distant metastasis in patients with head and neck squamous cell carcinoma. Oncotarget 6, 37398-37409. doi: 10.18632/ oncotarget.6054

Li, H., Duan, N., Zhang, Q., and Shao, Y. (2019). IL1A \& IL1B genetic polymorphisms are risk factors for thyroid cancer in a Chinese Han population. Int. Immunopharmacol. 76:105869. doi: 10.1016/j.intimp.2019.105869

Li, K., Huang, S. H., Lao, X. M., Yang, L., Liao, G. Q., and Liang, Y. J. (2018). Interaction of cancer cell-derived Foxp3 and tumor microenvironment in human tongue squamous cell carcinoma. Exp. Cell. Res. 370, 643-652. doi: 10.1016/j.yexcr.2018.07.029

Li, L., Wang, X. L., Lei, Q., Sun, C. Z., Xi, Y., Chen, R., et al. (2020). Comprehensive immunogenomic landscape analysis of prognosis-related genes in head and neck cancer. Sci. Rep. 10:6395.

Li, T., Fan, J., Wang, B., Traugh, N., Chen, Q., Liu, J. S., et al. (2017). TIMER: a web server for comprehensive analysis of tumor-infiltrating immune cells. Cancer Res. 77, e108-e110. doi: 10.1158/0008-5472.CAN-17-0307

Li, Y., Huang, J., Zeng, B., Yang, D., Sun, J., Yin, X., et al. (2018). PSMD2 regulates breast cancer cell proliferation and cell cycle progression by modulating p21 and p27 proteasomal degradation. Cancer Lett. 430, 109-122. doi: 10.1016/j.canlet. 2018.05.018

Li, Z., Liu, J., Li, L., Shao, S., Wu, J., Bian, L., et al. (2018). Epithelial mesenchymal transition induced by the CXCL9/CXCR3 axis through AKT activation promotes invasion and metastasis in tongue squamous cell carcinoma. Oncol. Rep. 39, 1356-1368. doi: 10.3892/or.2017.6169

Liu, E., Marin, D., Banerjee, P., Macapinlac, H. A., Thompson, P., Basar, R., et al. (2020). Use of CAR-transduced natural killer cells in CD19-positive lymphoid tumors. N. Engl. J. Med. 382, 545-553. doi: 10.1056/NEJMoa1910607

Liu, K., Chyr, J., Zhao, W., and Zhou, X. (2016). Immune signaling-based Cascade Propagation approach re-stratifies HNSCC patients. Methods 111, 72-79. doi: 10.1016/j.ymeth.2016.06.018

Liu, X., Xu, X., Deng, W., Huang, M., Wu, Y., Zhou, Z., et al. (2019). CCL18 enhances migration, invasion and EMT by binding CCR8 in bladder cancer cells. Mol. Med. Rep. 19, 1678-1686. doi: 10.3892/mmr.2018.9791

Long, J., Hu, Z., Xue, H., Wang, Y., Chen, J., Tang, F., et al. (2019). Vascular endothelial growth factor (VEGF) impairs the motility and immune function of human mature dendritic cells through the VEGF receptor 2-RhoA-cofilin1 pathway. Cancer Sci. 110, 2357-2367. doi: 10.1111/cas.14091

Lu, C., Huang, T., Chen, W., and Lu, H. (2015). GnRH participates in the selfrenewal of A549-derived lung cancer stem-like cells through upregulation of the JNK signaling pathway. Oncol. Rep. 34, 244-250. doi: 10.3892/or.2015.3956

Luger, D., Yang, Y. A., Raviv, A., Weinberg, D., Banerjee, S., Lee, M. J., et al. (2013). Expression of the B-cell receptor component CD79a on immature myeloid cells contributes to their tumor promoting effects. PLoS One 8:e76115. doi: 10.1371/journal.pone.0076115

Magnussen, S., Hadler-Olsen, E., Latysheva, N., Pirila, E., Steigen, S. E., Hanes, R., et al. (2014). Tumour microenvironments induce expression of urokinase plasminogen activator receptor (uPAR) and concomitant activation of gelatinolytic enzymes. PLoS One 9:e105929. doi: 10.1371/journal.pone. 0105929

Maitra, M., Wang, Y., Gerard, R. D., Mendelson, C. R., and Garcia, C. K. (2010). Surfactant protein A2 mutations associated with pulmonary fibrosis lead to protein instability and endoplasmic reticulum stress. J. Biol. Chem. 285, 2210322113. doi: 10.1074/jbc.M110.121467

Mei, S., Meyer, C. A., Zheng, R., Qin, Q., Wu, Q., Jiang, P., et al. (2017). Cistrome cancer: a web resource for integrative gene regulation modeling in cancer. Cancer Res. 77, e19-e22. doi: 10.1158/0008-5472.CAN-17-0327

Mhaidat, N. M., Al-azzam, S. I., Alzoubi, K. H., Khabour, O. F., and Gharaibeh, B. F. (2014). Granzyme B gene polymorphisms, colorectal cancer risk, and metastasis. J. Cancer Res. Ther. 10, 587-590. doi: 10.4103/0973-1482.137940

Miao, H., Ruan, S., and Shen, M. (2018). VEGF-C in rectal cancer tissues promotes tumor invasion and metastasis. J. BUON 23, 42-47.

Monisha, J., Roy, N. K., Bordoloi, D., Kumar, A., Golla, R., Kotoky, J., et al. (2017). Nuclear factor kappa B: a potential target to persecute head and neck cancer. Curr. Drug Targets 18, 232-253. doi: 10.2174/1389450117666160201112330
Nan, J., Wang, Y., Yang, J., and Stark, G. R. (2018). IRF9 and unphosphorylated STAT2 cooperate with NF-кB to drive IL6 expression. Proc. Natl. Acad. Sci. U.S.A. 115, 3906-3911. doi: 10.1073/pnas.1714102115

Ono, M. (2020). Control of regulatory T-cell differentiation and function by T-cell receptor signalling and Foxp3 transcription factor complexes. Immunology 160, 24-37. doi: 10.1111/imm.13178

Pakasticali, N., Gill, T., Chobrutskiy, B. I., Tong, W. L., Ramsamooj, M., and Blanck, G. (2019). TRAV gene segments further away from the TRAJ gene segment cluster appear more commonly in human tumor and blood samples. Mol. Immunol. 116, 174-179. doi: 10.1016/j.molimm.2019.10.010

Pan, X., Jiang, B., Liu, J., Ding, J., Li, Y., Sun, R., et al. (2017). STC1 promotes cell apoptosis via NF-кB phospho-P65 Ser536 in cervical cancer cells. Oncotarget 8, 46249-46261. doi: 10.18632/oncotarget.17641

Popeda, M., Stokowy, T., Bednarz-Knoll, N., Jurek, A., Niemira, M., Bielska, A., et al. (2019). NF-kappa B signaling-related signatures are connected with the mesenchymal phenotype of circulating tumor cells in non-metastatic breast cancer. Cancers 11:1961. doi: 10.3390/cancers11121961

Qin, X., Yan, M., Zhang, J., Wang, X., Shen, Z., Lv, Z., et al. (2016). TGFß3-mediated induction of Periostin facilitates head and neck cancer growth and is associated with metastasis. Sci. Rep. 6:20587. doi: 10.1038/srep20587

Qiu, J., Zhang, W., Zang, C., Liu, X., Liu, F., Ge, R., et al. (2018). Identification of key genes and miRNAs markers of papillary thyroid cancer. Biol. Res. 51:45. doi: 10.1186/s40659-018-0188-1

Ran, X., and Yang, K. (2017). Inhibitors of the PD-1/PD-L1 axis for the treatment of head and neck cancer: current status and future perspectives. Drug Des. Devel. Ther. 11, 2007-2014. doi: 10.2147/DDDT.S140687

Rao, S. V., Solum, G., Niederdorfer, B., Nørsett, K. G., Bjørkøy, G., and Thommesen, L. (2017). Gastrin activates autophagy and increases migration and survival of gastric adenocarcinoma cells. BMC Cancer 17:68. doi: 10.1186/ s12885-017-3055-5

Rosa, F. E., dos Santos, R. M., Poli-Frederico, R. C., Canevari Rde, A., Nishimoto, I. N., Magrin, J., et al. (2007). Shorter CAG repeat length in the AR gene is associated with poor outcome in head and neck cancer. Arch. Oral Biol. 52, 732-739. doi: 10.1016/j.archoralbio.2006.12.021

Ryan, N., Anderson, K., Volpedo, G., Hamza, O., Varikuti, S., Satoskar, A. R., et al. (2020). STAT1 inhibits T-cell exhaustion and myeloid derived suppressor cell accumulation to promote antitumor immune responses in head and neck squamous cell carcinoma. Int. J. Cancer 146, 1717-1729. doi: 10.1002/ijc. 32781

Saada-Bouzid, E., Peyrade, F., and Guigay, J. (2019). Molecular genetics of head and neck squamous cell carcinoma. Curr. Opin. Oncol. 31, 131-137. doi: 10. 1097/CCO.0000000000000536

Sambandam, Y., Sundaram, K., Liu, A., Kirkwood, K. L., Ries, W. L., and Reddy, S. V. (2013). CXCL13 activation of c-Myc induces RANK ligand expression in stromal/preosteoblast cells in the oral squamous cell carcinoma tumor-bone microenvironment. Oncogene 32, 97-105. doi: 10.1038/onc.2012.24

Sanmamed, M. F., and Chen, L. (2018). A paradigm shift in cancer immunotherapy: from enhancement to normalization. Cell 175, 313-326. doi: 10.1016/j.cell.2018.09.035

Schreiber, T. H., Wolf, D., Bodero, M., Gonzalez, L., and Podack, E. R. (2012). T cell costimulation by TNFR superfamily (TNFRSF) 4 and TNFRSF2 5 in the context of vaccination. J. Immunol. 189, 3311-3318. doi: 10.4049/jimmunol. 1200597

Sénécal, V., Deblois, G., Beauseigle, D., Schneider, R., Brandenburg, J., Newcombe, J., et al. (2016). Production of IL-27 in multiple sclerosis lesions by astrocytes and myeloid cells: modulation of local immune responses. Glia 64, 553-569. doi: 10.1002/glia.22948

Song, G., Liu, K., Yang, X., Mu, B., Yang, J., He, L., et al. (2017). SATB1 plays an oncogenic role in esophageal cancer by up-regulation of FN1 and PDGFRB. Oncotarget 8, 17771-17784. doi: 10.18632/oncotarget.14849

Sun, M., McDonald, S. J., Brady, R. D., O’Brien, T. J., and Shultz, S. R. (2018). The influence of immunological stressors on traumatic brain injury. Brain Behav. Immun. 69, 618-628. doi: 10.1016/j.bbi.2018.01.007

Sun, W., Shang, J., Zhang, J., Chen, S., and Hao, M. (2019). Correlations of DKK1 with incidence and prognosis of breast cancer. J. BUON 24, 26-32.

Thörnqvist, L., and Ohlin, M. (2018). The functional 3'-end of immunoglobulin heavy chain variable (IGHV) genes. Mol. Immunol. 96, 61-68. doi: 10.1016/j. molimm.2018.02.013 
Vasaikar, S., Tsipras, G., Landázuri, N., Costa, H., Wilhelmi, V., Scicluna, P., et al. (2018). Overexpression of endothelin B receptor in glioblastoma: a prognostic marker and therapeutic target? BMC Cancer 18:154. doi: 10.1186/s12885-0184012-7

Vivekanadhan, S., and Mukhopadhyay, D. (2019). Divergent roles of Plexin D1 in cancer. Biochim. Biophys. Acta Rev. Cancer 1872, 103-110. doi: 10.1016/j.bbcan. 2019.05.004

Wang, B., Khachigian, L. M., Esau, L., Birrer, M. J., Zhao, X., Parker, M. I., et al. (2009). A key role for early growth response-1 and nuclear factor-kappaB in mediating and maintaining GRO/CXCR2 proliferative signaling in esophageal cancer. Mol. Cancer Res. 7, 755-764. doi: 10.1158/1541-7786.MCR-080472

Wang, Y., Hu, Y., Guo, J., and Wang, L. (2019). miR-148a-3p suppresses the proliferation and invasion of esophageal cancer by targeting DNMT1. Genet. Test Mol. Biomarkers 23, 98-104. doi: 10.1089/gtmb.2018.0285

Weber, R., Meister, M., Muley, T., Thomas, M., Sültmann, H., Warth, A., et al. (2019). Pathways regulating the expression of the immunomodulatory protein glycodelin in non-small cell lung cancer. Int. J. Oncol. 54, 515-526. doi: 10.3892/ ijo.2018.4654

Wischatta, M., Sprinzl, G. M., Gunkel, A. R., Hussl, B., Romani, N., and SchrottFischer, A. (2000). Dendritic cells in selected head and neck tumors. Ann. Otol. Rhinol. Laryngol. 109, 56-62. doi: 10.1177/000348940010900111

Xue, K., Li, J., Nan, S., Zhao, X., and Xu, C. (2019). Downregulation of LINC00460 decreases STC2 and promotes autophagy of head and neck squamous cell carcinoma by up-regulating microRNA-206. Life Sci. 231:116459. doi: 10.1016/ j.lfs.2019.05.015

Yan, B., Li, H., Yang, X., Shao, J., Jang, M., Guan, D., et al. (2013). Unraveling regulatory programs for NF-kappaB, p53 and microRNAs in head and neck squamous cell carcinoma. PLoS One 8:e73656. doi: 10.1371/journal.pone. 0073656

Ye, W., Zhou, Y., Xu, B., Zhu, D., Rui, X., Xu, M., et al. (2019). CD247 expression is associated with differentiation and classification in ovarian cancer. Medicine 98:e18407. doi: 10.1097/MD.0000000000018407
Yu, G., Wang, L. G., Han, Y., and He, Q. Y. (2012). clusterProfiler: an R package for comparing biological themes among gene clusters. OMICS 16, 284-287. doi: 10.1089/omi.2011.0118

Zeng, W., Li, H., Chen, Y., Lv, H., Liu, L., Ran, J., et al. (2016). Survivin activates NF-кB p65 via the IKK $\beta$ promoter in esophageal squamous cell carcinoma. Mol. Med. Rep. 13, 1869-1880. doi: 10.3892/mmr.2015.4737

Zhang, S., Zhang, E., Long, J., Hu, Z., Peng, J., Liu, L., et al. (2019). Immune infiltration in renal cell carcinoma. Cancer Sci. 110, 1564-1572. doi: 10.1111/ cas. 13996

Zhang, S. C., Hu, Z. Q., Long, J. H., Zhu, G. M., Wang, Y., Jia, Y., et al. (2019). Clinical implications of tumor-infiltrating immune cells in breast cancer. J. Cancer 10, 6175-6184. doi: 10.7150/jca.35901

Zhao, X., Shen, F., Ma, J., Zhao, S., Meng, L., Wang, X., et al. (2020). CREB1induced miR-1204 promoted malignant phenotype of glioblastoma through targeting NR3C2. Cancer Cell Int. 20:111. doi: 10.1186/s12935-020-01176-0

Zhou, J., Yang, Y., Zhang, Y., Liu, H., and Dou, Q. (2018). A meta-analysis on the role of pleiotrophin (PTN) as a prognostic factor in cancer. PLoS One 13:e0207473. doi: 10.1371/journal.pone.0207473

Zhou, X., Ma, L., Li, J., Gu, J., Shi, Q., and Yu, R. (2012). Effects of SEMA3G on migration and invasion of glioma cells. Oncol. Rep. 28, 269-275. doi: 10.3892/ or.2012.1796

Conflict of Interest: The authors declare that the research was conducted in the absence of any commercial or financial relationships that could be construed as a potential conflict of interest.

Copyright (C) 2020 Long, Zhang, Zeng, Ouyang, Wang, Hu, Ye, Wu, Jin, Zhou and Zeng. This is an open-access article distributed under the terms of the Creative Commons Attribution License (CC BY). The use, distribution or reproduction in other forums is permitted, provided the original author(s) and the copyright owner(s) are credited and that the original publication in this journal is cited, in accordance with accepted academic practice. No use, distribution or reproduction is permitted which does not comply with these terms. 